\title{
Understanding the costs of urban rail transport operations
}

\author{
Anupriya*, Daniel J. Graham, Jose M. Carbo, Richard J. Anderson, Prateek Bansal \\ Transport Strategy Centre \\ Department of Civil and Environmental Engineering \\ Imperial College London \\ South Kensington Campus \\ London $S W 7$ 2AZ
}

\begin{abstract}
There is considerable variation in the average cost of operations across urban rail transport (or metro) systems. Since metros are typically owned and operated by public authorities, there is a public interest case in understanding the key drivers of their operational costs. This paper estimates short-run cost functions for metro operations using a unique panel dataset from twenty-four metro systems around the world. We use a flexible translog specification and apply dynamic panel generalised method of moments (DPGMM) estimation to control for confounding from observed and unobserved characteristics of metro operations. Our empirical results show that metro systems with a high density of usage are the most cost-efficient. We also find that operational costs fall as metro size increases. These results have important implications for the economic appraisal of metro systems.
\end{abstract}

Keywords: urban rail transport, operational costs, unobserved productivity, scale economies, endogeneity

\section{Declarations of interest: None.}

Funding: This research did not receive any specific grant from funding agencies in the public, commercial, or not-for-profit sectors.

${ }^{*}$ Corresponding author. Email address: anupriya15@imperial.ac.uk 


\section{Introduction}

By 2050, nearly sixty-eight percent of the world's population will be living in cities, that is an increase of two and a half billion people on the present urban population (UNDESA, 2018). To cater for the needs of the growing urban travel demand, cities around the world are increasingly investing in high-capacity urban rail transportation systems, also known as metros. According to the International Association of Public Transport, around forty-five new metros have been opened in the last decade and another twohundred new metro-lines are expected over the next five years ${ }^{1}$. Metros, therefore, are very important in attaining urban mobility requirements. Comparison of average costs (that is, cost per unit car-kilometre) of metro operations reveals considerable variation across systems. Figure 1 shows average operational costs in 2015 for a group of thirty-two metro systems, normalised with respect to the mean value of the group. The normalised average cost ranges from 0.5 to 3.0, showing that the order of magnitude of unit operational costs for some metros is six times higher than others. Since metros are typically owned and operated by public authorities, there is a public interest case in understanding the underlying technology that determines the observed differences in unit costs.

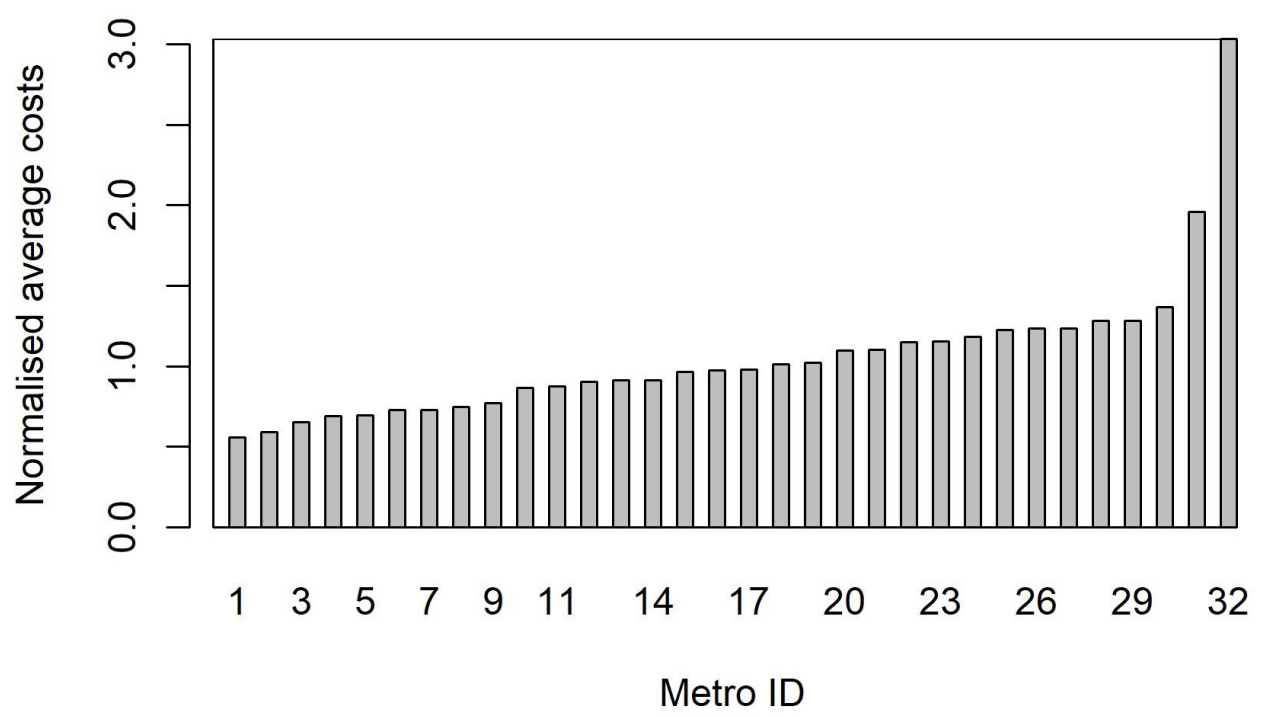

Figure 1: Normalised average costs of urban metro operations, 2015.

There exists a large volume of research dedicated to the empirical analysis of transportation costs. The estimation of cost functions is important to compare the performance

\footnotetext{
${ }^{1}$ https://www.uitp.org/world-metro-figures-2018
} 
of firms over time and across different regulatory regimes. It also facilitates a broad characterisation of the industry by determining the extent of scale economies. Cost studies thus have numerous applications ranging from input/output analysis and guiding investments to supporting decisions on pricing rules and organisation of market structure (Small et al., 2007). While previous studies have mostly analysed cost structures and productivity for main line railways and for the airlines industry, the academic literature on analysis of costs of metro operations is relatively scarce.

One of the main challenges for the existing literature is treatment of endogenous covariates in the estimation of a metro cost function. The assumption that covariates such as output and factor prices are fixed and known to the firm a priori is misleading. As metro firms typically have market power, there are unobserved firm-level sources of efficiency or productivity that play an important role in determining the firm's decision on the quantity of its output and its level of input prices. These covariates are thus endogenously determined by the firm. Some previous attempts to address such confounding issues focus only on endogeneity of firm output through the application of instrumental variables (IV) estimation to linear cost models (Savage, 1997; Mizutani, 2004). However, most of the past studies do not offer adequate control for firm level unobserved sources of confounding. This lack of control on endogenous covariates can result in biased estimates of the scale economies in provision of metro services (Greene, 1980). These scale economy estimates, (i) returns to network size and (ii) returns to density, develop our understanding of the technology driving unit-cost differences in the metro industry. We find that there may be inconsistency between the scale economy estimates from the literature and the observed behaviour in the metro industry. While the weight of evidence in the literature supports constant returns to network size, metro firms have been found to expand their network over time (Basso et al., 2011). Some researchers rightly suggest that even without any significant cost savings, metro firms may expand their network due to a host of reasons including serving more of a city in order to justify raising subsidy funds for a citywide tax, economic development and so on. However, we argue that in addition to these reasons, there may be various other sources that may result into true cost advantages for metro firms when they expand their networks. For instance, as suggested by Graham et al. (2003), in cases where sufficient latent demand exists, a metro firm may try to exploit the density economies by expanding the network. Such cost savings may not be reflected 
in the estimates of economies of scale from the literature.

In this research, we estimate the causal relationship between short-run metro operational costs and output using a flexible translog specification and dynamic panel generalised method of moments (DPGMM) estimation. The application of DPGMM can effectively deal with endogeneity in various covariates in the cost-output relationship. To our knowledge, this is the first time that a transport cost function has been studied using such econometric methods. The original DPGMM formulation used in this study were introduced by Arellano and Bover (1995) and Blundell and Bond (2000) for the estimation of production functions with unobserved firm level confounding. Here, we apply these developments to the analysis of costs using the fact that a cost function is dual to its production technology.

In this paper, we make use of a unique panel dataset that has been collected by the Transport Strategy Centre (TSC) at Imperial College London since 1994. The data relate to twenty-four metro systems around the world. In contrast to previous studies that mostly use country specific data on metro systems (for instance, Savage (1997) uses data on US metro systems), we combine data from metros of varied sizes and operational characteristics from all over the world. We thus develop an inclusive understanding of the short-run operational cost structure for the metro industry. We also provide estimates of some important descriptors of the underlying technology that are the nature of scale economies, input factor separability and homotheticity.

The major contributions of this research can be summarised as follows:

1. We contribute with a unique and very high quality panel data to estimate the technology underlying cost of short-run operations of metro systems.

2. We develop a rigorous understanding of the endogeneity issues in the empirical estimation of the cost function and apply an appropriate econometric framework to address these issues.

3. We provide new and more reliable empirical insights into the external sources of cost-efficiency for metro systems.

This paper is organised as follows. Section 2 reviews the relevant literature. Section 3 describes the data and variables. Section 4 explains the properties and advantages of DPGMM by comparing it with traditional econometric approaches used in the cost function literature. Section 5 presents a simulation to compare parameter estimates from 
different methodologies. Section 6 presents our results. Section 7 presents an application of our scale economy estimates to understand the variation in unit operational costs across metro systems. Conclusions and implications for policy are presented in the final section.

\section{Literature Review}

The literature on the estimation of transport cost functions and the nature of scale economies in the provision of transport services is well known and several extensive reviews can be found in Jara-Diaz (1982), Oum and Waters (1996) and Basso et al. (2011). In this section, we discuss scale economies and endogeneity issues in the cost function estimation, and highlight how developments in the production function estimation can be employed to correctly estimate the cost function.

\subsection{Scale Economies}

Conventionally, researchers derive two main descriptors of industry behaviour from cost studies: economies of scale and economies of density. Economies of scale or returns to scale (RTS) describe the relationship between average costs and overall scale of operations varying both output and network size, that is, they reflect returns to firm size. Economies of density or returns to density (RTD) refer to the relationship between average costs and output keeping network size fixed. Jara-Diaz and Cortes (1996) and Basso and Jara-Diaz (2006) suggest the use of economies of spatial scope ${ }^{2}$ in place of RTS as they point out that RTS analyses the effect of increasing network size but with same density of traffic movements along each link in the network. RTS estimates, however, are still widely used to explain network expansions (refer the literature review summary Table 7 attached in the appendix) because as Batarce (2016); Batarce and Galilea (2018) point out, the exact definition of economies of spatial scope is difficult to apply using an aggregate measure of output. Therefore, in this analysis we focus on RTS and RTD estimates.

Although the literature on the analysis of cost structures and productivity for mainline railways is huge, studies focusing on the costs of urban rail transport operations is relatively scarce. The cost characteristics of metro systems do not necessarily correspond

\footnotetext{
${ }^{2} \mathrm{~A}$ transport firm produces movements of different types (passengers or freight) between different origins and destinations (ODs) at different time periods. The final output of a transport firm is actually a vector $Y=y_{i j t}$, where $y_{i j k t}$ represents flow between OD pair $i j$ at time period $t$. Economies of spatial scope measures the cost advantages (or disadvantages) of jointly producing two sets of outputs (Refer Basso and Jara-Díaz (2005) for an example application).
} 
to those of mainline railways (Graham et al., 2003), however, we review the mainline railway literature to develop an understanding of the determinants of costs in the railway industry in general. The mainline railway literature indicates the presence of increasing RTD over a wide range of output (see Table 7 in Appendix A for a summary of results from key literature). Increasing RTD arises due to the existence of a range of fixed and semi-fixed costs in the railway industry that do not vary proportionally with output (Graham et al., 2003). The results on the existence of RTS are inconsistent (refer Table 7). The majority support the prevalence of constant RTS implying that railway firms do not have significant cost advantages in expanding their networks. However, railway firms have been found to expand their networks over time and this observed behaviour is inconsistent with the constant RTS estimates from the literature (Jara-Diaz, 1982; Oum and Waters, 1996; Basso et al., 2011). A limited few cost studies (Pozdena and Merewitz, 1978; Savage, 1997) and productivity studies (Graham et al., 2003; Graham, 2008) on urban rail transport (see Table 7 in Appendix A) draw similar conclusions. It is evident that the RTS estimates are unable to explain the network expansions in the industry. This has stimulated the growth of many interesting facets in the literature, from identifying and controlling for endogeneity issues in cost function estimation, to application of new estimation methods, to redefinition of traditional descriptors of the technology in the industry. The following paragraphs summarise the main findings.

\subsection{Endogeneity Challenges in Cost Function Estimation}

Early studies on transport cost functions assume that covariates in a cost model are fixed or exogenously determined (see Jara-Diaz (1982); Oum and Waters (1996) for details). To support the assumption on exogeneity of the output variable, these studies argue that since firms are regulated and fares are normally imposed externally, firms cannot influence their level of demand. Thus, the level of output produced by the firm is known to the firm a priori. This assumption can lead to problem of endogeneity in estimation because a firm's decision on the quantity of its output should depend upon its level of productivity that cannot be directly observed. Moreover, Jara-Diaz (1982) rightly adds in criticism of the output exogeneity assumption that, (i) not all firms are regulated, and (ii) demand levels are also influenced by the level of service (crowding, reliability etc.) in addition to fares. A few studies, for instance Savage (1997) consider output as endogenous and use instrument variables influencing demand like population 
density per unit area. Although exogeneity of these instruments has been argued based on investigation of the data used in this study, their generalisation to other studies is questionable. Similar assumptions on exogeneity of factor prices (for example, see Savage (1997)) can aggravate the bias in the estimated parameters. This assumption is again backed by the unrealistic argument that transport firms do not have the ability to control their input prices. Some studies use exogenous factor prices like gross domestic product per capita for labour prices (for instance, see Karlaftis and McCarthy (2002)) as proxies for actual factor prices to overcome this bias in the estimation. However, these proxies do not take into account the actual productivity differences between firms (Borts, 1960). We argue that if a firm has buying power, then it is quite feasible for the firm to set its input prices in the short-run in response to the input quantities and its productivity. Input prices are thus endogenous ${ }^{3}$. In order to reduce the correlation between variables of a transport cost function and its error term, researchers have also added hedonic characteristics or attributes of output ${ }^{4}$ to the cost specification, which control for the differences in operational conditions and network characteristics between firms (JaraDiaz, 1982; Oum and Waters, 1996). However, some of these hedonic characteristics are endogenous. We introduce a methodological framework for cost function estimation that can appropriately control for endogeneity in multiple covariates.

\subsection{Endogeneity due to Unobserved Inefficiencies}

The main assumption behind a cost function is that the firm minimises the expenses incurred in producing a given level of output. A related strand in the literature hypothesises that transport firms may not be cost minimising due to several reasons including (i) threat posed by competitive forces and elastic demand or (ii) technical inefficiencies due to existence of a regulatory framework (as mentioned in Basso et al. (2011)). ${ }^{5}$ More

\footnotetext{
${ }^{3}$ Refer section 3 for a discussion on the various input prices for a metro firm and the type of control the metro firm may have over these prices in the short-run and in the long-run.

${ }^{4}$ Examples of hedonic characteristics include average length of haul that captures the characteristics of the market served by the transport system (Caves et al., 1981) and indicators for peaking such as peak-to-base ratio intended to capture the overall productivity of the factors of production and those for average loads (Savage, 1997).

${ }^{5}$ The first point relates to issues of cross-efficiency in a market where a transport firm may have a few effective competitors or threat from a potential entrant. Under such a scenario, the operational structure of the firm not only influences its own costs and demand but also the profit of its competitor firms. For instance, the transport firm may adopt a service frequency or a route structure that may not necessarily be cost minimising, however, such a structure allows it to increase its own demand at the expense of its competitor. The second point corresponds to a framework under which a regulatory agent
} 
recently, techniques like data envelopment analysis have been used to account for these unobserved inefficiencies in the cost model. Gagnepain and Ivaldi (2002) argue that the cost frontiers estimated using these techniques are capable to correct for the problem of endogeneity in traditional regression analysis. However, we argue that even in the presence of these sources of inefficiencies firms may exhibit cost minimising behaviour subject to constraints. Therefore, to obtain valid conclusions from our estimated cost models, it is important to account for these unobservables in the cost function estimation. To support our hypothesis, we discuss some key findings from the complimentary production function literature in the rest of this section.

\subsection{Production Function Estimation}

Past few decades of research in total factor productivity (TFP) analysis has seen interesting developments particularly on empirical front (refer (Beveren, 2012) for a comprehensive review of these developments). The main caveats identified are: (i) TFP analysis using traditional methods like pooled ordinary least squares (POLS) estimation introduces simultaneity or endogeneity bias because a firm's unobserved productivity shocks and its input choices are likely to be correlated (De-Loecker, 2011). (ii) Selection bias emerges if no allowance for entry and exit are made, as entry and exit decisions are systematically related to unobserved productivity differences. Input choices of a firm are conditional on its survival and in turn on these unobserved productivity differences (Ackerberg et al., 2007). (iii) In the presence of imperfect competition, using industrylevel price indices or scheduled rates as proxies for firm-level prices leads to a biased representation of the firm's productivity level (Katayama et al., 2009). This is because a firm sets its input price in response to its input quantity and productivity.

In essence, unobserved productivity has been recognised to play a key role in the TFP analysis. Not accounting for this unobserved productivity can lead to erroneous estimates of coefficients associated with factor inputs and underestimation of returns to scale. Studies on TFP analysis have evolved progressively to develop estimation methodologies that can appropriately control for the unobserved productivity in the estimation of production

asks a transport firm to produce a given level output and in turn covers the associated costs. However, the regulator has limited knowledge of the firm's production technology. This may impact the input allocation and cost reducing efforts of the firm and thus, the firm may not be cost-minimising at a given level of output. 
function (for example, see Olley and Pakes (1996), Blundell and Bond (2000), Levinsohn and Petrin (2003), Wooldridge (2009) and so on).

Since the cost function is the dual characterisation of the firm's production technology, all relevant covariates present in a firm's production function should also be embodied in its cost function. In this study, we address the deficiencies in the estimation of a metro cost function by applying the developments summarised above in the production function literature.

\section{Data and Relevant Variables}

In this section we describe the variables that are used in this analysis along with their respective sources and hypotheses. We make use of data that has been collected by two consortia of metro system operators, namely the Community of Metros (CoMET) and the Nova Group of Metros (Nova) ${ }^{6}$ since 1994, managed by the Transport Strategy Centre (TSC) at Imperial College London. The consortia focus on benchmarking using an extensive dataset comprising of key performance indicators related to 38 metro operations in 36 cities around the world ${ }^{7}$. However, the dataset has several missing values depending upon the extent of information that is reported by the metro operator during each year. Accordingly, we obtain an unbalanced panel dataset with 165 observations consisting of 24 systems over 14 years, between 2003 and 2016. The high-standard quality of this dataset is worth noting, as during the years of benchmarking work, the dataset has been cleaned systematically using one-to-one verification with operators and validation tests. Due to the sensitive commercial nature of the TSC data, we present our results in an anonymised form.

For the purpose of this study, we use data on operational costs, as well as a set of covariates used in the literature that are fundamental in describing the relationship between transport costs and output, derived on the basis of production-cost duality.

\section{Cost Variable}

This analysis deals with short-run variable costs of operation of metro systems. We use the data on total operating costs, that is, the sum of all costs of operations of the

\footnotetext{
${ }^{6}$ https://cometandnova.org/

${ }^{7}$ These metros are represented in figure 5 in Appendix B.
} 
system including maintenance of rolling stock and way and structure, however, excluding capital investments, either related to depreciation or asset renewals as these are fixed in the short-run. The main components of the total operating cost variable are service $\operatorname{costs}^{8}$, administration $\operatorname{costs}^{9}$ and maintenance $\operatorname{costs}^{10}$ (see figure 6 in Appendix B).

The cost data have been converted to 2016 international dollar equivalent using a purchasing power parity (PPP) index ${ }^{11} 12$ published by the World Bank. We observe that the literature is inconsistent in terms of defining the short-run variable costs of metro operations. The studies that estimate constant RTS mostly assume that way and structure maintenance costs are fixed in the short-run (refer Table 7 in Appendix A) and exclude these costs from short-run cost analysis. However, maintenance costs in the short-run comprise both fixed and variable costs. The fixed component of maintenance costs relate to costs that can be capitalised, for instance, costs spent on asset renewals or depreciation costs. However, there exists other rolling stock and infrastructure maintenance costs in addition to these fixed costs. Our TSC dataset suggests that over eighty-percent of these way and structure maintenance cost components are driven by labour and electricity. In the short-run, such maintenance costs can thus be flexibly adjusted in response to changes in planned outputs. Figure $2 \mathrm{a}$ shows the variation of average way and structure maintenance costs over output as measured in car-kilometres as per the TSC dataset. We also show the variation of the components of way and structure maintenance costs as reported in the TSC dataset (see figure $2 \mathrm{~b}$ and figure 2c). Average maintenance costs roughly increase with output indicating that these cost components are variable in the short-run.

\footnotetext{
${ }^{8}$ Service costs comprise the energy and labour costs required to move the train along the network and to operate the stations. Such costs, for instance, include train service costs related to drivers and traction, service costs related to ticketing, revenue control, police and security, among others.

${ }^{9}$ Administrative costs refers to all engineering and project costs and general administration costs for the metro, for instance, costs related to marketing, revenue development, human resource development, information systems and communications technology, expenditure on public or corporate relations, purchasing, contracting, procurement and so on.

${ }^{10}$ Maintenance costs consist of the costs of maintaining all the assets used by the train, that is, track, station and rolling stock. These include costs that cannot be capitalised in the short-run, for instance, costs related to cleaning of rolling stock and stations and train service parts, and do not include any capital investments, for instance, asset renewals.

${ }^{11}$ https://data.worldbank.org/indicator/NY.GDP.MKTP.PP.CD.

${ }^{12}$ Although the use of the World Bank PPP indices for international cost comparisons has its own limitations, however, this is a standard convention adopted in the literature for empirical work of this type.
} 


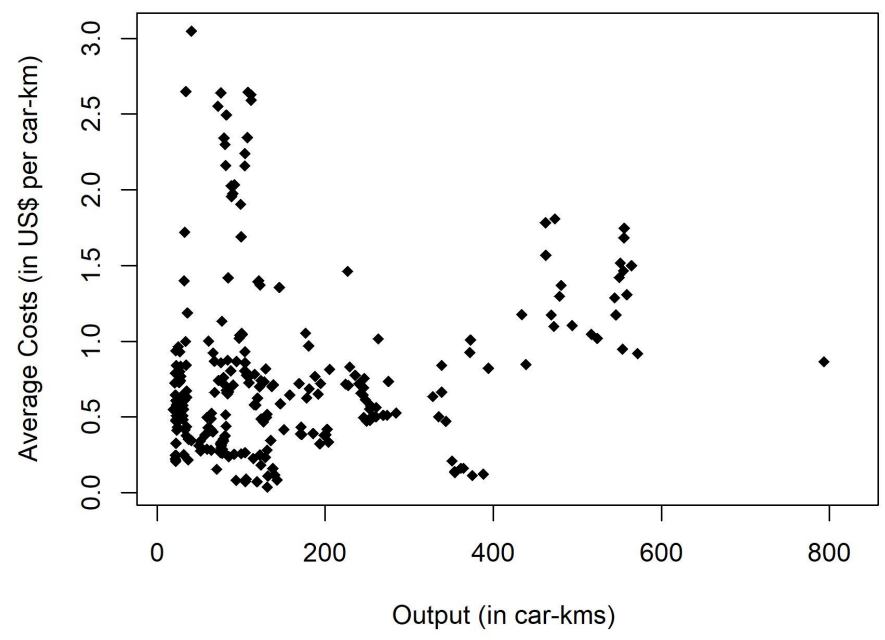

(a) Variation of Average Way and Structure Maintenance Costs (in 2016 US\$ equivalent per $\mathrm{km}$ ) over Output (in car-kms in millions)

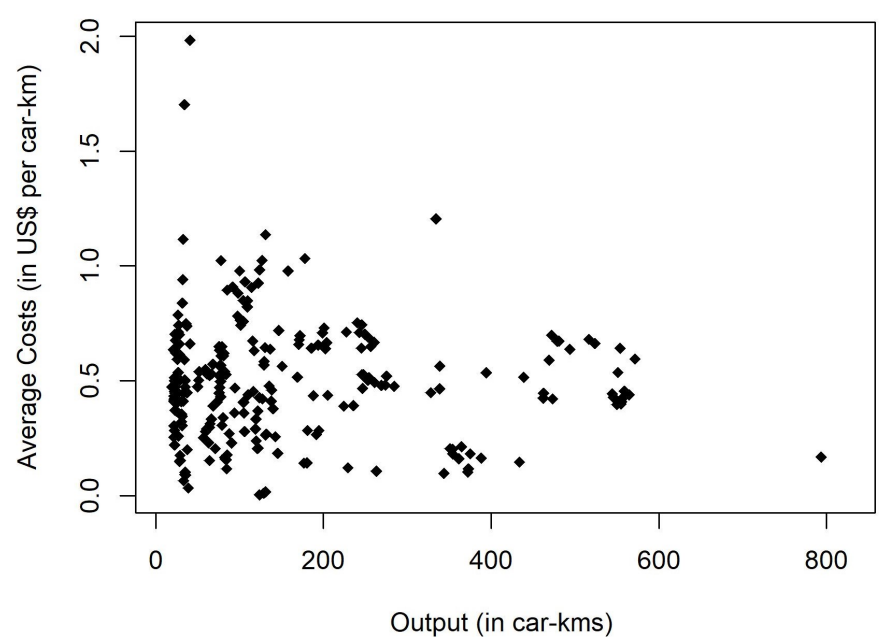

(b) Variation of Average Infrastructure Maintenance Costs (in 2016 US \$ equivalent per $\mathrm{km}$ ) over Output (in car-kms in millions)

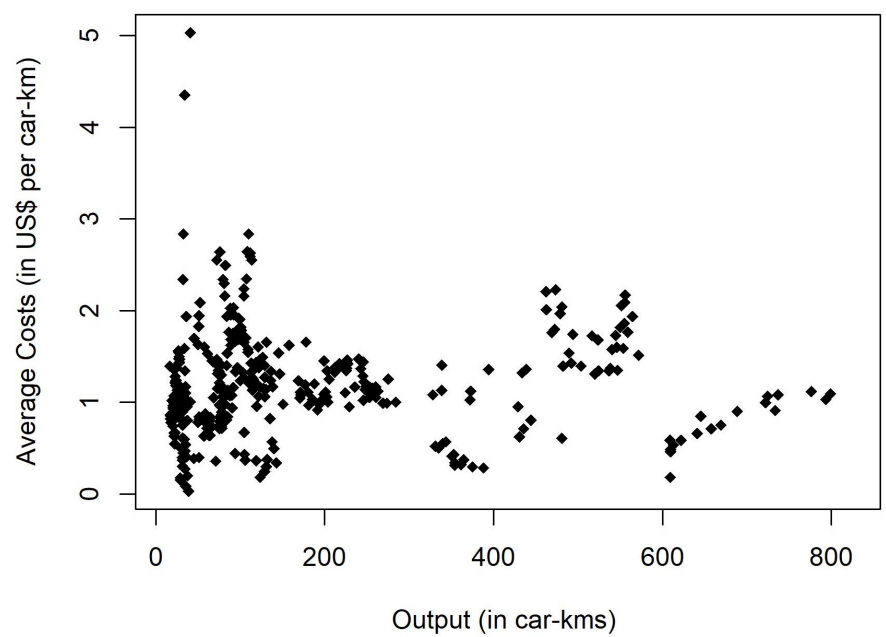

(c) Variation of Average Station Facilities Maintenance Costs (in 2016 US\$ equivalent per $\mathrm{km}$ ) over Output (in car-kms in millions)

Figure 2: Variation of Average Maintenance Cost Components over Output 


\section{Output}

Actual car kilometres operated in revenue service is the primary aggregated measure of output in this analysis. We also use a secondary measure of output that captures terminal expenses driven by passenger usage. This measure is a load factor variable calculated as passenger kilometres divided by revenue car kilometres. Passenger kilometres refers to the sum of distances travelled by all passengers including fare evaders. We control for the endogeneity of both these output variables in our estimation.

\section{Fixed factors}

We use network size as the measure of the fixed factor of production, which is measured as the length of the network used by trains operating in service. That is, it refers to the sum of all lines excluding tracks in depots, yards and sidings and those used by trains for turning movements.

\section{Factor prices}

The literature suggests that in the presence of imperfect competition, firms set their input price in response to their respective input requirements and productivity (refer section 2.2). Therefore, we treat all factor prices as endogenous ${ }^{13}$ and calculate these prices based on the data itself. We include three variable inputs: labour, energy and residuals. The TSC data reports two components of total labour costs,-- own labour costs and contracted labour costs and their corresponding labour hours. We calculate unit price for labour by dividing the total labour costs by total labour hours and unit energy (electricity) costs as total energy costs divided by total energy consumption (reported in megawatt hours). We then convert these prices into 2016 international dollar equivalent.

The residual expenses in operations, that is, non-labour and non-energy costs are converted to unit prices by dividing total residual expenses (total operating costs minus total labour costs minus total energy costs) by capacity kilometres. Capacity kilometres represents a standardised measure of capacity that includes both seating and standing capacity, calculated by normalising standing density to four people per square metre. Residual price relates to the price of materials and services, which could not be capitalised, for instance, price of parts, cleaning materials, insurance, telecommunication services and

\footnotetext{
${ }^{13}$ In Appendix D, we carry out a robustness test to demonstrate the effect of treatment of factor prices as exogenous on the estimated parameters of our cost model.
} 
so on ${ }^{14}$.

Firstly, we discuss the sources of endogeneity in labour prices. A metro firm usually has to recruit from a large pool of the labour market. Most of the labour skills can be taught or trained, however, even specialist trained workers, for instance, train drivers, usually have the choice to work somewhere else. Therefore, minimum wages are usually subject to the labour market and the metro management has very limited control over these prices even if it is a very large employer. Although the management cannot fix wages downwards due to competition in the market, however, several years of benchmarking experience at the TSC suggests that the management often pays more than the market wage. Therefore, we argue that the metro firm may decide its labour price in response to its labour requirements and productivity in the short-run.

In the context of energy prices, the metro firm can leverage buying power because it is a huge buyer of electricity. It is the volume and long-term assurance over the sale of electricity which in general drives down the price of electricity for the metro firm. Thus, the metro firm has the ability and buying power to hedge prices in the short-run. However, long term prices with the supply market will eliminate these short term price fluctuations. On similar lines, we argue that the residual prices may be decided by the metro firm in the short-run.

Table 1 provides descriptive statistics for all variables used in the analysis. Appendix F reports the variation of all variables for different metro systems over time.

Table 1: Summary statistics for variables used in the analysis.

\begin{tabular}{lrrrrrr}
\hline Variable & Obs. & Min & Max & Median & Mean & Std.Dev \\
\hline Operational Costs (m) (PPP US\$) & 165 & 58.92 & 3152.31 & 431.78 & 695.27 & 626.48 \\
Car Kilometres (m) & 165 & 19.35 & 793.60 & 91.90 & 124.76 & 110.40 \\
Load Factor & 165 & 17.38 & 82.84 & 49.53 & 49.01 & 17.13 \\
Network length (km) & 165 & 35.60 & 588.00 & 86.20 & 132.78 & 122.61 \\
Labour Price (PPP US\$/h) & 165 & 5.09 & 61.33 & 27.23 & 29.74 & 14.14 \\
Energy Price (PPP US\$/MWh) & 165 & 0.025 & 0.403 & 0.169 & 0.172 & 0.082 \\
Residual Price (PPP US\$/cap.km) & 165 & 0.001 & 0.029 & 0.005 & 0.005 & 0.003 \\
\hline
\end{tabular}

*Legend: Obs.: Observations, Std. Dev.: Standard Deviation, m: millions, cap.: capacity

\footnotetext{
${ }^{14}$ The operational cost models for metros in the literature do not include any material price, however we argue that the inclusion of this price is important as these residual expenses comprise approximately $20 \%$ of short-run operational costs of metros, which is quite a substantial part. In Appendix E, we carry out a robustness test to demonstrate the effect of exclusion of residual prices on the estimated parameters of our cost model.
} 


\section{Methodology}

\subsection{Theoretical framework}

At any output level $y$, a producer chooses the level of input prices $\mathbf{w}$ that leads to the minimum cost $C$ of producing $y$. For a three factor Cobb Douglas production technology with one of the factors being fixed in the short-run, the short-run cost function is the solution to the following optimisation problem:

$$
\begin{aligned}
C^{s}\left(y, \mathbf{w}, \overline{x_{3}}\right)= & \min _{x_{1}, x_{2}} w_{1} x_{1}+w_{2} x_{2}+w_{3} \overline{x_{3}} \\
& \text { such that } \\
y & =e^{\omega} x_{1}^{\alpha} x_{2}^{\beta} \overline{x_{3}} \gamma
\end{aligned}
$$

where, $x_{1}$ and $x_{2}$ are the variable factors of production and $w_{1}$ and $w_{2}$ are corresponding factor prices. $\overline{x_{3}}$ is the fixed factor of production with corresponding factor price $w_{3} . \alpha, \beta$ and $\gamma$ are constants representing the elasticities of output with respect to the associated factor of production. $\omega$ stands for the unobserved productivity differences between firms. Our definition of the production technology $y$ is consistent with the recent production function literature (refer section 2), which suggests that $\omega$ is rudimentary in the definition of $y$.

The above constrained optimisation problem can be solved via the Lagrangian function:

$$
L\left(y, \mathbf{w}, \overline{x_{3}}, \lambda\right)=w_{1} x_{1}+w_{2} x_{2}+w_{3} \overline{x_{3}}+\lambda\left[y-e^{\omega} x_{1}^{\alpha} x_{2}^{\beta}{\overline{x_{3}}}^{\gamma}\right]
$$

This gives the following first order conditions:

$$
\begin{gathered}
\frac{\partial L}{\partial x_{1}}=w_{1}-\lambda e^{\omega} \alpha x_{1}^{\alpha-1} x_{2}^{\beta} \bar{x}_{3}^{\gamma}=w_{1}-\lambda \alpha \frac{y}{x_{1}}=0 \\
\frac{\partial L}{\partial x_{2}}=w_{2}-\lambda e^{\omega} \beta x_{2}^{\beta-1} x_{1}^{\alpha} \bar{x}_{3}^{\gamma}=w_{2}-\lambda \beta \frac{y}{x_{2}}=0 \\
\frac{\partial L}{\partial \lambda}=y-e^{\omega} x_{1}^{\alpha} x_{2}^{\beta} \bar{x}_{3}^{\gamma}=0
\end{gathered}
$$

Solving the above equations, we get $x_{1}=\frac{\lambda \alpha y}{w_{1}}, x_{2}=\frac{\lambda \beta y}{w_{2}}$, and $\lambda=\left(\frac{y^{(1-\alpha-\beta)} w_{1}^{\alpha} w_{2}^{\beta}}{e^{\omega} \alpha^{\alpha} \beta^{\beta} \overline{x_{3}^{\gamma}}}\right)^{\frac{1}{(\alpha+\beta)}}$. Substituting these back in the cost equation $C^{s}\left(y, \mathbf{w}, \overline{x_{3}}\right)$ and separating the variable component from the total short-run cost, we get the short-run variable cost function, 
which is as follows:

$\log C V^{s}\left(y, \mathbf{w}, \omega, \overline{x_{3}}\right)=\alpha_{0}+\frac{\alpha}{\alpha+\beta} \log w_{1}+\frac{\beta}{\alpha+\beta} \log w_{2}+\frac{1}{\alpha+\beta} \log y-\frac{\gamma}{\alpha+\beta} \log \overline{x_{3}}-\frac{\omega}{\alpha+\beta}$

We see that the unobserved productivity term ' $\omega$ ' ends up in the cost function. Since more productive firms are more likely to produce more output, $C$ and $\omega$ are negatively correlated. Thus in absence of $\omega$, the scale economy estimates obtained from empirical cost analysis will have a downward bias as we observe bigger firms to have lower unit costs (Collard-Wexler, 2012). Equation 1 is illustrative and can be generalised to include multiple factors of production. A second-order Taylor-series expansion of the terms of equation 2 yields a translog cost function that is most commonly used in transport cost studies.

\subsection{The empirical model}

The short-run variable cost function for a metro firm $i, i=1, \ldots, N$ at time $t, t=$ $1, \ldots, T, C V_{i t}^{s}(y, \mathbf{w}, N, \omega)$, can be represented by:

$$
\begin{aligned}
\log C V_{i t}^{s} & =\alpha_{0}+\alpha_{y} \log y_{i t}+\sum_{j} \alpha_{j} \log w(j)_{i t}+\alpha_{N} \log N_{i t}+\beta_{y y}\left(\log y_{i t}\right)^{2} \\
& +\beta_{N N}\left(\log N_{i t}\right)^{2}+\sum_{j} \sum_{k} \beta_{j k} \log w(j)_{i t} \log w(k)_{i t}+\sum_{j} \beta_{j y} \log w(j)_{i t} \log y_{i t} \\
& +\sum_{j} \beta_{j N} \log w(j)_{i t} \log N_{i t}+\beta_{y N} \log y_{i t} \log N_{i t}+\delta_{t}+\omega_{i t}+\epsilon_{i t}, \quad j, k=1, \ldots K
\end{aligned}
$$

where $y$ is a measure of output, w is a vector of prices for ' $K$ ' variable inputs, $N$ is network size that represents capital stock, $\omega$ is the unobserved productivity level of the firm, $\delta_{t}$ are year dummies that capture the year-specific effects on productivity, $\epsilon$ is a normally distributed idiosyncratic error term or in other words, all random shocks to the short-run operating costs. We normalise each variable by its mean value to obtain an approximation of a firm's cost structure around mean production level (Friedlaender and Spady, 1981).

It is required that the cost function be homogeneous of degree one and concave in 
variable factor prices (McFadden, 1978). The following restrictions are imposed on the parameters to ensure linear homogeneity in factor prices:

$$
\begin{aligned}
& \sum_{i=1}^{K} \alpha_{i}=1, \quad \beta_{i j}=\beta_{j i} \quad \forall i, j \\
& \sum_{i=1}^{K} \beta_{i j}=\sum_{i=1}^{K} \beta_{j i}=\sum_{i=1}^{K} \beta_{i y}=\sum_{i=1}^{K} \beta_{i N}=0
\end{aligned}
$$

Concavity in factor prices is ensured if the sub-matrix of the bordered Hessian matrix of the cost function $C V^{s}(y, \mathbf{w}, N, \omega)$ corresponding to the factor prices has non-positive eigenvalues at each observation.

The cost function is also required to have positive marginal costs, given by,

$$
\begin{aligned}
\frac{\partial C V^{s}(y, \mathbf{w}, N, \omega)}{\partial y} & =\frac{\partial \log C V^{s}(y, \mathbf{w}, N, \omega)}{\partial \log y} \frac{C V^{s}}{y} \\
& =\alpha_{y}+2 \beta_{y y}(\log y)+\sum_{j} \beta_{j y} \log w(j)+\beta_{y N} \log N, \quad j=1, \ldots K
\end{aligned}
$$

The conditional factor share equations for input $i$ can be derived directly by partially differentiating the cost function equation 3 with respect to the price of input $i$ and using Shepherd's lemma:

$$
\begin{aligned}
\frac{\partial \log C V^{s}(y, \mathbf{w}, N, \omega)}{\partial \log w_{i}} & =\frac{\partial C V^{s}(y, \mathbf{w}, N, \omega)}{\partial w_{i}} \frac{w_{i}}{C V^{s}(y, \mathbf{w}, N, \omega)}=\frac{w_{i} x_{i}}{C V^{s}(y, \mathbf{w}, N, \omega)} \\
& =s_{i}(y, \mathbf{w}, N, \omega) \\
& =\alpha_{i}+\sum_{j=1}^{K} \beta_{i j} \log w_{j}+\beta_{i y} \log y+\beta_{i N} \log N+\xi_{i} ; j=1, \ldots K .
\end{aligned}
$$

We calculate short-run estimates of returns to density (RTD) and returns to scale 
(RTS) as follows:

$$
\begin{aligned}
R T D= & \left(\frac{\partial \log C V^{s}}{\partial \log y}\right)^{-1} \\
= & \left(\alpha_{y}+2 \beta_{y y} \log y+\beta_{y N} \log N+\sum_{i} \beta_{i y} \log w_{i}\right)^{-1} \\
R T S= & \left(\frac{\partial \log C V^{s}}{\partial \log y}+\frac{\partial \log C V^{s}}{\partial \log N}\right)^{-1} \\
= & \left(\alpha_{y}+2 \beta_{y y} \log y+\beta_{y N} \log N+\sum_{i} \beta_{i y} \log w_{i}\right. \\
& \left.+\alpha_{N}+2 \beta_{N N} \log N+\beta_{y N} \log y+\sum_{i} \beta_{i N} \log w_{i}\right)^{-1}
\end{aligned}
$$

RTD and RTS estimates greater than (less than) one implies increasing (decreasing) returns to scale and density respectively.

Using equation 6, we also calculate the own price elasticities of demand for each input, represented by $e_{i}$, and the Allen-Uzawa partial elasticities of substitution between different inputs, given by $\sigma_{i j}$. These elasticities are defined as follows:

$$
\begin{aligned}
& e_{i}=\frac{\beta_{i i}}{s_{i}}+s_{i}-1, \quad i=1, \ldots K . \\
& \sigma_{i j}=\frac{\beta_{i j}}{s_{i} s_{j}}+1, \quad i, j=1, \ldots K, \quad i \neq j .
\end{aligned}
$$

If $\sigma_{i j}$ is less than(greater than) zero, factors $i$ and $j$ are complements (substitutes).

\subsection{Econometric Estimation}

We apply four commonly used panel methods from most to least restrictive: (i) pooled ordinary least squares (POLS), (ii) fixed effects (FE), (iii) instrumental variables (IV), and (iv) dynamic panel generalised methods of moments (DPGMM).

\section{Pooled Ordinary Least Squares (POLS) Estimation}

The traditional POLS estimation assumes constant coefficients and uses the GaussMarkov conditions. In this approach, $\omega_{i t}$ is left in the error term. The observations are pooled across $i$ and $t$ and OLS estimation is applied.

$$
C V_{i t}^{s}=\gamma X_{i t}^{\prime}+\delta_{t}+\nu_{i t}, \text { where } \nu_{i t}=\omega_{i t}+\epsilon_{i t}
$$


where $X_{i t}$ denotes the set of covariates in the short-run cost model.

Consistency of this estimator requires the contemporaneous exogeneity assumptions (a) $\operatorname{Cov}\left(X_{i t}, \omega_{i t}\right)=0$ and (b) $\operatorname{Cov}\left(X_{i t}, \epsilon_{i t}\right)=0$ for all $t=1, \ldots, T$. The former assumption is highly restrictive as it requires that the level of input prices and output for any firm are independent of its productivity (refer section 2 ).

\section{Fixed Effects (FE) Estimation}

This approach offers the treatment of firm level time-invariant heterogeneity by inclusion of a fixed firm-specific anticipated component of productivity as $\omega_{i t}=\omega_{i}$. FE estimates are obtained by applying OLS estimation to the time-demeaned form or within transformation of Equation 14.

$$
C \ddot{V}_{i t}^{s}=\gamma \ddot{X}_{i t}^{\prime}+\delta_{t}+\ddot{\epsilon_{i t}}
$$

where $C \ddot{V}_{i t}^{s}=C V_{i t}^{s}-C \bar{V}_{i}^{s}$ and so on.

For consistency of this estimator, strict exogeneity assumption on the covariates $\left\{X_{i t}\right\}$ is required, that is, $\operatorname{Cov}\left(X_{i s}, \epsilon_{i t}\right)=0$ for all $s, t=1,2, \ldots, T$. So situations where shocks today affect future decisions about the covariates are ruled out. This assumption is unrealistic as it is quite feasible for metro operators to set their input prices in response to their input requirements and productivity and future decisions on the share of factor inputs employed in the production of a certain level of output are determined by present shocks to productivity. For instance, these shocks to productivity may include any technological innovation in the past year that reduces labour share in the production process (Rios-Rull and Santaeulalia-Llopis, 2010). Moreover, as noted by Caves et al. (1987), time-demeaning of covariates yields unreasonably low coefficients of the fixed factor of production and thus biases the estimates of scale economies.

\section{Instrumental Variables}

To allow for correlations between the covariates of our cost model and shocks to the short-run operating cost, we use a vector of time-varying instrumental variables (IVs), given by $Z_{i t}$ that are uncorrelated with the idiosyncratic errors $\epsilon_{i t}$ and strongly correlated with the covariate vector $X_{i t}$. Estimates are obtained by first applying first-differencing to eliminate time-invariant heterogeneity as in equation 11, followed by IV estimation. This again requires strict exogeneity of IVs, that is, $\operatorname{Cov}\left(Z_{i s}, \epsilon_{i t}\right)=0$; for all $s, t=1,2, \ldots, T$, 
for consistency.

$$
\Delta C V_{i t}^{s}=\gamma \Delta X_{i t}^{\prime}+\delta_{t}+\Delta \epsilon_{i t}
$$

where $\Delta C V_{i t}^{s}=C V_{i t}^{s}-C V_{i, t-1}^{s}$ and so on.

In the case of a metro cost function, one may think of potential external instruments such as demographic patterns at the city level for metro output and economic growth the national level for input prices. There are previous studies in the literature, for instance, Savage (1997), that use external instruments like population density for output. Demographic patterns in a city, for instance, population density, does determine the demand for metro services and in turn its output. However, the fact that these patterns also determine the operational costs of metros due to associated presence of economies of density in metro operations, is something that has at large received undue attention. Therefore, in our opinion, the exogeneity of such external instruments is questionable.

Similarly, instruments for input prices such as economic growth at the national level are again not truly exogenous. Higher economic growth implies increased number of economic opportunities, which perhaps may result in increased demand for metro services and consequently affect the metro output. Again, any change in metro output will possibly affect the unit operational costs of metros due to associated presence of strong economies of density and scale.

In the absence of suitable IVs, suitable instruments can be derived from the panel nature of the dataset. Lagged levels of endogenous covariates can be used as their instruments for differenced equations. In this case, consistency of the estimator relies on the sequential exogeneity assumption that input prices and outputs are chosen before anything is known of $\epsilon_{i t}$, that is, $\operatorname{Cov}\left(X_{i s}, \epsilon_{i t}\right)=0$ for all $s \leq t .{ }^{15}$ Under sequential exogeneity, $\Delta \epsilon_{i t}=\epsilon_{i t}-\epsilon_{i, t-1}$ is uncorrelated with the past history of the covariates,

\footnotetext{
${ }^{15}$ One may argue that a metro firm is highly likely to predict the future factors that may impact its productivity, such as future demand and future prices of inputs. However, these predictions correspond to future values of covariates in the cost model. All random shocks to operating costs, represented by $\epsilon$, in the future years cannot be predicted by the firm and are thus unobserved. Therefore, the sequential exogeneity assumption is sufficient and lagged levels of endogenous covariates are consistent to achieve identification.
} 
$X_{i, t-1}^{o} \equiv\left(X_{i 1}, X_{i 2}, \ldots, X_{i, t-1}\right)$. This generates the moment conditions:

$$
E\left(X_{i, t-1}^{o} \Delta \epsilon_{i t}\right)=0, \quad t=2, \ldots, T
$$

Difference Generalised Method of Moments (GMM) estimation is applied to equation 11 using the above moment conditions (Arellano and Bond, 1991). To assure that we have strong instruments, it is important that our covariates are not highly persistent over time. System GMM provides an augmented approach to overcome any weak instrument problem. As suggested by Arellano and Bover (1995), additional moment conditions are generated for estimation by adding lagged first differences of covariates as instruments in the levels equation (14):

$$
E\left[\Delta X_{i t}^{\prime}\left(C V_{i t}^{s}-\bar{\omega}_{i}-\gamma X_{i t}^{\prime}\right]=0, \quad t=2, \ldots, T\right.
$$

where $\bar{\omega}_{i}=E\left(\omega_{i}\right)$.

Consistency of the GMM estimators described above depends on two crucial assumptions: (i) there should be no first order serial-autocorrelation in the error term of the levels equation (14), and (ii) the instruments should be exogenous. Two tests are available to evaluate these assumptions. The Arellano and Bond test (Arellano and Bond, 1991) evaluates the hypothesis that there is no second-order serial correlation in the error term of the first differenced equation (11). This implies that the errors from the levels equation (14) are serially uncorrelated. Deeper time lags are tested when serial correlation exists. Validity of instruments is tested using the Sargan/Hansen test of over-identifying restrictions.

It is worth emphasising here that we apply GMM estimation to a translog cost model. For endogenous covariates, the second order interaction terms will also be endogenous. So we need to instrument all endogenous covariates and their second order interactions with other covariates. This will result in a large set of instruments for a translog cost model with endogenous covariates.

\section{Dynamic Panel Generalised Methods of Moments (DPGMM)}

Time-demeaning and first-differences operations mentioned previously lead to complete elimination of the cross-sectional variation in time-invariant covariates, resulting into a downward bias in the estimated parameter for the fixed factor of production. To 
overcome this problem, we use a dynamic panel model for metro costs that allows us to investigate firm dynamics and adjustments in behaviour conditional on costs in the previous time period.

$$
C V_{i t}^{s}=\rho C V_{i, t-1}^{s}+\gamma X_{i t}^{\prime}+\delta_{t}+\omega_{i t}+\epsilon_{i t}
$$

This model is in accordance with Blundell and Bond (2000) where the time invariant nature of productivity is relaxed by allowing the firm to react to previous shocks to its productivity, that is, by decomposing the productivity term into a fixed effect and an auto-regressive $\operatorname{AR}(1)$ component: $\omega_{i t}=\rho \omega_{i, t-1}+\xi_{i t}$. From equation 14, we have the following levels and first-differenced equations:

$$
\begin{aligned}
& C V_{i t}^{s}=\rho C V_{i, t-1}^{s}+\gamma X_{i t}^{\prime}+\delta_{t}+\omega_{i t}+\epsilon_{i t}, \quad t=1, \ldots, T . \\
& \Delta C V_{i t}^{s}=\rho \Delta C V_{i, t-1}^{s}+\gamma \Delta X_{i t}^{\prime}+\delta_{t}+\Delta \epsilon_{i t}, \quad t=2, \ldots, T .
\end{aligned}
$$

The minimal assumptions imposed are that the dynamics are first order:

$$
E\left(C V_{i s}^{s} \epsilon_{i t}\right)=0 ; \quad s=0,1, \ldots, t-1 ; \quad t=1,2, \ldots, T
$$

Parameter estimates are derived by applying the difference GMM or system GMM estimation based on whether our covariates are highly persistent over time or not.

\section{Simulations}

The properties of panel estimators are well understood. In this brief section we demonstrate the problem of endogeneity and the potential of different panel estimators in the specific setting of cost function estimation with endogenous productivity and the resulting estimates of economies of scale and density. For demonstration, we use a Cobb-Douglas cost function but our conclusions are equally applicable for a more flexible specification like translog.

Our simulations are conducted on samples of 1000 observations comprising of 100 firms each observed over 10 years. We index firms by $i, i=(1, \ldots, N)$ and time points by $t, t=\left(1, \ldots, n_{i}\right)$ giving a total of $n=\sum_{i=1}^{N} n_{i}$ observations. The model set-up follows a 
Cobb-Douglas AR(1) cost function structure with the covariates mentioned in Table 1:

$$
\log C V_{i t}=\alpha_{y} \log y_{i t}+\alpha_{l} \log l_{i t} \sum_{j} \alpha_{j} \log w_{j, i t}+\alpha_{N} \log N_{i t}+\omega_{i t}+\mu_{i t}, \quad j=1, \ldots, 4
$$

The variables $y_{i t}, l_{i t}, N_{i t}, \mathbf{w}_{\mathbf{i t}}, \omega_{i t}$ and $\mu_{i t}$ represent the primary output variable, load factor, network length, vector of factor prices, unobserved productivity and random shocks to productivity respectively for firm $i$ at time $t$. We introduce three possible sources of confounding into the model: a relationship between the lagged dependent variables and the current independent variable, serial correlation in error and positive correlations between the unobserved productivity $\omega_{i t}$ and the endogenous independent variables. We model the development of all the independent variables in their logarithmic form as given in equation 18. Serial correlation is introduced by including an auto-correlated shock $\mu_{i t}$ that is independent but exhibits the same variance across the sample as given in equation 19. The parameter $\omega_{i t}$ represents the unobserved-time variant effect that is positively correlated with all the endogenous regressors. We assume that the analyst is ignorant of its presence in the true data generating process for the dependent variable.

$$
\log X_{i t}=\rho \log X_{i, t-1}+\gamma \log Y_{i, t-1}+\epsilon_{i t}
$$

where $X_{i t}$ denotes the set of covariates in equation 17 .

$$
\log \omega_{i t}=\rho \log \omega_{i, t-1}+\eta_{i t}
$$

with $\epsilon_{i t} \sim N(0,1), \eta_{i t} \sim N(0,1)$ and $\omega_{i, 1} \sim N(0,1)$.

The parameters $\rho$ and $\gamma$ are set to 0.7 and 0.07 respectively. The chosen value of $\alpha$ parameters of Equation 17 are listed in Table 2 under the column $\alpha_{\text {true }}$. We generate a panel with a length of 15 observations for each unit, and subsequently ignore the first 5 observations for the estimation of parameters. We apply the different methodologies detailed in Section 4.3 to estimate the coefficients of Equation 17.

Table 2 reports the estimated coefficients, their associated standard errors and root mean squared errors (RMSE). The results from static panel methods exhibit an upward 
Table 2: Simulation Results for a Cobb-Douglas cost function using different estimation methodologies.

(a) Simulation Results from Static Panel Methods.

\begin{tabular}{lrrrrrrrrrrrrrr}
\hline & \multicolumn{1}{c}{ POLS } & $\overline{1}$ & \multicolumn{1}{c}{ FE } & \multicolumn{1}{c}{ IV: Diff GMM } & \multicolumn{1}{c}{ IV: Sys GMM } \\
Coef. & $\alpha_{\text {true }}$ & $\bar{\alpha}$ & $\sigma$ & RMSE & $\bar{\alpha}$ & $\sigma$ & RMSE & $\bar{\alpha}$ & $\sigma$ & RMSE & $\bar{\alpha}$ & $\sigma$ & RMSE \\
\hline$\alpha_{y}$ & 0.640 & 1.212 & 0.043 & 0.574 & 0.858 & 0.040 & 0.222 & 0.713 & 0.085 & 0.112 & 1.113 & 0.081 & 0.480 \\
$\alpha_{N}$ & 0.177 & 0.674 & 0.045 & 0.499 & 0.398 & 0.040 & 0.224 & 0.277 & 0.071 & 0.122 & 0.500 & 0.074 & 0.331 \\
$\alpha_{l}$ & 0.298 & 0.827 & 0.042 & 0.531 & 0.580 & 0.038 & 0.284 & 0.455 & 0.078 & 0.176 & 0.845 & 0.070 & 0.551 \\
$\alpha_{1}$ & 0.485 & 0.507 & 0.038 & 0.044 & 0.537 & 0.032 & 0.061 & 0.526 & 0.062 & 0.074 & 0.528 & 0.061 & 0.075 \\
$\alpha_{2}$ & 0.208 & 0.201 & 0.039 & 0.040 & 0.204 & 0.033 & 0.033 & 0.257 & 0.058 & 0.076 & 0.208 & 0.057 & 0.057 \\
$\alpha_{3}$ & 0.307 & 0.292 & 0.039 & 0.042 & 0.259 & 0.033 & 0.058 & 0.217 & 0.067 & 0.112 & 0.265 & 0.066 & 0.078 \\
$\rho$ & 0.700 & & & & & & & & & & & & \\
RTD & 1.563 & 0.825 & 0.029 & 0.738 & 1.166 & 0.054 & 0.401 & 1.402 & 0.166 & 0.231 & 0.898 & 0.065 & 0.667 \\
RTS & 1.224 & 0.530 & 0.015 & 0.694 & 0.796 & 0.032 & 0.429 & 1.010 & 0.118 & 0.244 & 0.620 & 0.043 & 0.606 \\
\hline
\end{tabular}
(b) Simulation Results from Dynamic Panel Methods.

\begin{tabular}{lrrrrrrr}
\hline & \multicolumn{4}{c}{$\mathrm{AR}(1):$ Diff GMM } & \multicolumn{3}{c}{$\mathrm{AR}(1)$ : Sys GMM } \\
Coef. & $\alpha_{\text {true }}$ & $\bar{\alpha}$ & $\sigma$ & $\mathrm{RMSE}$ & $\bar{\alpha}$ & $\sigma$ & $\mathrm{RMSE}$ \\
\hline$\alpha_{y}$ & 0.640 & 0.485 & 0.065 & 0.168 & 0.648 & 0.056 & 0.057 \\
$\alpha_{N}$ & 0.177 & 0.138 & 0.057 & 0.069 & 0.241 & 0.054 & 0.083 \\
$\alpha_{l}$ & 0.298 & 0.235 & 0.057 & 0.085 & 0.395 & 0.050 & 0.109 \\
$\alpha_{1}$ & 0.485 & 0.476 & 0.039 & 0.040 & 0.436 & 0.039 & 0.062 \\
$\alpha_{2}$ & 0.208 & 0.195 & 0.043 & 0.045 & 0.116 & 0.040 & 0.100 \\
$\alpha_{3}$ & 0.307 & 0.328 & 0.045 & 0.050 & 0.448 & 0.044 & 0.147 \\
$\rho$ & 0.700 & 0.353 & 0.033 & 0.348 & 0.609 & 0.024 & 0.094 \\
RTD & 1.563 & 2.062 & 0.276 & 0.571 & 1.543 & 0.134 & 0.135 \\
RTS & 1.224 & 1.606 & 0.224 & 0.443 & 1.125 & 0.088 & 0.132 \\
\hline
\end{tabular}


bias in the estimated coefficients of the output and network length variables. Thus the resulting estimates of RTD and RTS from these models have a downward bias. This confirms our hypothesis that with the erroneous omission of the unobserved productivity confounder $\omega_{i t}$, the resulting estimates of scale economies from a cost model have a downward bias. The inclusion of fixed effects in a cost model fails to adjust for this source of confounding, since by construction, the fixed effects are independent of the covariates and therefore only capture time-invariant unobserved variables. Dynamic panel methods deliver parameter and RTS and RTD estimates that indicate relatively small biases and root mean squared errors. This is because they can control for both the endogeneity of covariates resulting from the erroneous omission of $\omega_{i t}$ and the inherent dynamics of production process as explained in Section 4.3. Thus they offer enormous flexibility in approximating the dynamics of the production process while providing adequate adjustment for confounding covariates.

\section{Results and Discussion}

\subsection{Estimation Results of the cost model}

We apply the panel data estimators discussed in section 4.3 to estimate equation 3. The full table of results, Table 8, is attached in Appendix C. Using DPGMM estimation, we find both increasing returns to scale and density as compared to POLS estimates that reveal constant returns to scale (refer to Table 9 in Appendix C). It is evident that there is a downward bias in RTD and RTS estimates if the dynamics of firm-level productivity and the endogeneity in covariates remain unaccounted for. These results are consistent with our conclusions from the simulation analysis presented in Section 5.

We discuss our results from the DPGMM estimation (see Table 3) in this section. The reduced form regressions $\Delta X_{i t}$ on the past history of covariates $X_{i, t-1}^{o} \equiv\left(X_{i, 1}, X_{i, 2}, \ldots X_{i, t-1}\right)$ show low levels of correlation and suggests that there is a weak instrument problem. So, we use system GMM estimation. Results of Arellano-Bond tests for $\mathrm{AR}(1)$ and $\mathrm{AR}(2)$ and Sargan test of over-identifying restriction are also reported in Table 3. The Sargan test confirms that the use of GMM estimation is consistent and the Arellano-Bond tests confirm that the instruments are relevant. We end up with a large number of instruments (as reported in Table 3) because most of the covariates and their second order interactions in our translog specification are endogenous. The signs of estimated coefficients 
are consistent with economic theory, although low significance levels can be attributed to fewer observations or increase in the error variance in the IV estimation.

The estimated cost function has positive marginal costs for all observations. We also find that the estimated function is concave in factor prices for 108 out of 165 observations $^{16}{ }^{17}$. The exceptions relate to observations where eigenvalues for labour price are significantly greater than zero at the 95 percent confidence level. One way to deal with non-concavity is to impose local concavity using the method suggested in Ryana and Wales (2000). However, Ogawa (2011) shows that imposing any concavity condition misspecifies the cost model when firms are incapable of minimising their production costs due to extraneous circumstances. For instance, if a firm has many quasi-fixed inputs in the short-run, then it incurs additional costs such as those related to readjustment of their organisational structure and the relocation of employees (Pindyck and Rotemberg, 1983). Therefore, imposing concavity yields inconsistent estimates of the cost function parameters and leads to biased conclusions about the underlying production technology of the firm. Pindyck and Rotemberg (1983) and Ogawa (2011) suggest not to impose concavity, rather missing variables representing these additional costs that may be correlated with the factor prices should be controlled to obtain unbiased parameter estimates of a cost function. We believe that with the treatment of factor prices as endogenous covariates and the use of suitable instruments, we adjust for potential biases in the cost function estimation that may occur due to such missing variables.

\subsection{Properties of the underlying production technology}

Using the estimated cost function, we test the hypothesis of linear input factor separability and homotheticity of the underlying production technology. Factor separability implies that the marginal rate of technical substitution between two inputs is invariant with the prices of other inputs. This requires that the second order interactions of factor

\footnotetext{
${ }^{16}$ To check whether the estimated cost function is concave in factor prices, we perform a test of the hypothesis that the sub-matrix of the bordered Hessian matrix corresponding to factor prices has non-positive eigenvalues. We obtain the eigenvalues corresponding to each factor and their associated standard errors via bootstrapping.

${ }^{17}$ Savage (1997) and Mizutani (2004) adopt a translog specification of the cost function and the estimated cost function is concave in factor prices at 90 percent of the observations in their studies. However, their specifications do not consider any second order interactions of factor prices with output, that is, they assume that the underlying production technology is homothetic, which is a major limitation of their work. When Ogawa (2011) and Karlaftis and McCarthy (2002) used a fully flexible translog specification, the estimated cost functions were concave at around 40 percent and 70 percent observations respectively.
} 
Table 3: Estimates of the cost function parameters and associated robust standard errors.

\begin{tabular}{|c|c|c|}
\hline Explanatory variable & Estimate & Std. Error \\
\hline Car kms & $0.640^{* * *}$ & 0.116 \\
\hline Network length & $0.177^{*}$ & 0.097 \\
\hline Load Factor & $0.298^{*}$ & 0.160 \\
\hline Labour Price & $0.485^{* * *}$ & 0.048 \\
\hline Energy Price & $0.208^{* * *}$ & 0.046 \\
\hline Residual Price & $0.307^{* * *}$ & 0.056 \\
\hline Car kms ${ }^{2}$ & 0.390 & 0.299 \\
\hline Network length ${ }^{2}$ & 0.322 & 0.288 \\
\hline Load Factor $^{2}$ & 0.376 & 0.278 \\
\hline Labour Price $^{2}$ & $0.140^{*}$ & 0.083 \\
\hline Energy Price ${ }^{2}$ & $0.162^{* * *}$ & 0.060 \\
\hline Residual Price $^{2}$ & 0.011 & 0.032 \\
\hline Car kms x Network length & -0.640 & 0.579 \\
\hline Car kms x Load Factor & 0.244 & 0.410 \\
\hline Car kms x Labour Price & 0.028 & 0.159 \\
\hline Car kms x Energy Price & -0.200 & 0.158 \\
\hline Car kms x Residual Price & $0.172^{* *}$ & 0.076 \\
\hline Network length x Load Factor & -0.628 & 0.448 \\
\hline Network length x Labour Price & -0.210 & 0.157 \\
\hline Network length x Energy Price & $0.340^{* *}$ & 0.147 \\
\hline Network length x Residual Price & -0.130 & 0.103 \\
\hline Load Factor x Labour Price & $0.506^{* * *}$ & 0.188 \\
\hline Load Factor x Energy Price & $-0.459 * * *$ & 0.156 \\
\hline Load Factor x Residual Price & -0.047 & 0.092 \\
\hline Labour Price x Energy Price & $-0.145^{* *}$ & 0.066 \\
\hline Labour Price x Residual Price & 0.005 & 0.049 \\
\hline Energy Price x Residual Price & -0.016 & 0.046 \\
\hline Lag (Dependent Variable) & $0.196^{* * *}$ & 0.064 \\
\hline Year Effects Included & YES & \\
\hline No. of Observations & 119 & \\
\hline No. of Instruments & 139 & \\
\hline Arellano-Bond test for $\mathrm{AR}(1)$ & $\mathrm{z}=-1.86$ & $\operatorname{Pr}>z=0.052$ \\
\hline Arellano-Bond test for $\operatorname{AR}(2)$ & $\mathrm{z}=1.21$ & $\operatorname{Pr}>\mathrm{z}=0.226$ \\
\hline Sargan Test of over-identifying restrictions: & $\chi^{2}(103)=412.14$ & $\operatorname{Pr}>\chi^{2}=0.000$ \\
\hline
\end{tabular}

Notes:

(1) All explanatory variables are in their logarithmic form except for dummy variables.

(2) Significance: $(* * *) 99$ percent, $(* *) 95$ percent, $\left({ }^{*}\right) 90$ percent.

(3) Standard Errors reported are robust standard errors. 
prices are zero, that is, $\beta_{i j}=0$ for all $i, j$. At the $95 \%$ confidence level, factor separability was rejected.

Homotheticity implies that the marginal rate of technical substitution between factor inputs is homogeneous of degree zero, that is, the factor shares are invariant with the firm size. A necessary and sufficient condition for homotheticity of the underlying production technology is linear homogeneity in factor prices (equation 4) combined with a restriction that the second order interactions between factor price and output variables are zero, that is, $\beta_{i y}=0$ for all $i$. At the $95 \%$ confidence level, some second order interaction terms between the primary and secondary measures of output load factor and factor prices are significantly different from zero. Non-homotheticity implies that changes in factor price will affect both the cost elasticity and corresponding factor demand. Therefore, the scale economies are not independent of the input prices used in the production process.

Table 4 reports the own price elasticities of demand for factor inputs and the partial elasticities of substitution between different inputs (refer equation 8). Due to low significance levels of estimated elasticities, it is difficult to make definite conclusions regarding firm behaviour.

Table 4: Price elasticities of factor demand and elasticities of substitution

\begin{tabular}{lcccc}
\hline Elasticity & Estimate & Standard Error & $95 \%$ Confidence Interval \\
\hline$e_{1}$ & -0.226 & 0.176 & -0.570 & 0.119 \\
$e_{2}$ & -0.014 & 0.295 & -0.593 & 0.564 \\
$e_{3}$ & $-5.170^{* * *}$ & 1.303 & -7.724 & -2.617 \\
$\sigma_{12}$ & -0.442 & 0.664 & -1.743 & 0.858 \\
$\sigma_{13}$ & $1.035^{* * *}$ & 0.332 & 0.384 & 1.686 \\
$\sigma_{23}$ & 0.746 & 0.708 & -0.642 & 2.135 \\
\hline
\end{tabular}

(i) $e$ : own-price elasticity of demand, $\sigma$ : Allen partial elasticity of substitution.

(ii) notations: 1 = labour, $2=$ energy, $3=$ residual.

(iii) Significance: (***) 99 percent, (**) 95 percent, (*) 90 percent.

\subsection{Economies of Density and Scale}

Table 5 reports the estimates of returns to density (RTD) and scale (RTS) calculated using equation 7 .

At the sample mean, the estimated value of RTD is 1.562 that is statistically greater than unity and implies substantial economies of density. We find that, on an average, if the use of factors associated with density increases by $10 \%$, the average cost of metro operations increases by $6.4 \%$ only. This implies that there are significant cost advantages associated with a more intense use of a fixed network achieved by increasing operated 
car kilometres. Thus systems with higher density of operations face lower unit costs. There are a number of fixed and semi-fixed costs in urban rail operations, for instance, station staffing, which result into economies of density. Our finding on existence of RTD in urban rail transport operations is consistent with the literature. The magnitude of RTD estimates from previous studies vary between 1.2 to 1.5 , with the average value being around 1.4. Our POLS estimate of 1.227 (refer Table 8 in Appendix C) lies in this range. Thus, the estimates in the literature clearly have a downward bias due to the reasons mentioned previously.

Table 5: Summary of RTD and RTS estimates.

\begin{tabular}{lcclc}
\hline & Estimate & Std. Error & \multicolumn{2}{l}{$95 \%$ Confidence Interval } \\
\hline RTD & 1.562 & 0.283 & 1.006 & 2.117 \\
RTS & 1.223 & 0.081 & 1.065 & 1.381 \\
\hline
\end{tabular}

However, as demand is usually inelastic in car-kilometres, an increase in car-kilometres will depress the load factor variable and this will consequently lead to an increase in the magnitude of the economies of density (Jara-Diaz and Cortes, 1996). At mean values of all variables, our estimated cost model indicates that the elasticity of operational costs with respect to load factor is 0.298 . Using the value of average elasticity of transit use with respect to transit service frequency, also known as headway elasticity as reported in Litman (2004), which equals 0.5 , the adjusted values of economies of density will be::

$$
\left(\frac{1}{1.562}-\frac{0.5}{2} * 0.298\right)^{-1}=1.768
$$

We also find that there are economies of scale in urban rail transport operations. Our estimate of RTS is 1.223 , which is statistically greater than one. Thus, on an average, if a metro firm expands its network size and output proportionally by $10 \%$, the average costs of operations only increase by $8.18 \%$. Therefore, there are cost savings associated with expansion of a metro service. The literature mostly suggests existence of constant returns to scale in provision of metro services. Our POLS estimate of RTS is 1.045 (refer Table 8 in Appendix C) that is not statistically different from unity. Downward bias in the RTS estimates from the literature due to reasons previously discussed is once again evident. Moreover, our analysis includes track maintenance costs as a component of variable costs in the short-run. Scale economies in provision of metro services may result from the presence cost complementarities between operational costs and way and track 
maintenance cost components, as in case of mainline railways (Bitzan, 2000, 2003; Ivaldi and McCullough, 2007).

While past researchers rightly suggest that metro firms may expand their networks due to extraneous reasons such as to serve more areas in a city in response to rising travel demand, to justify raising subsidy funds for a citywide tax and economic development, among others, our estimate suggests that there may be other factors in addition to the above that may result into actual cost advantages for metros when they expand their networks. For instance, as Graham et al. (2003) suggest, in cases where sufficient latent demand exists, a metro firm may try to exploit the density economies by expanding the network. In addition, as Wei and Hansen (2003) note, when traffic increases significantly, crowding may drive costs up if frequency is increased. In such cases, network expansions may result into network wide savings in costs for a metro firm.

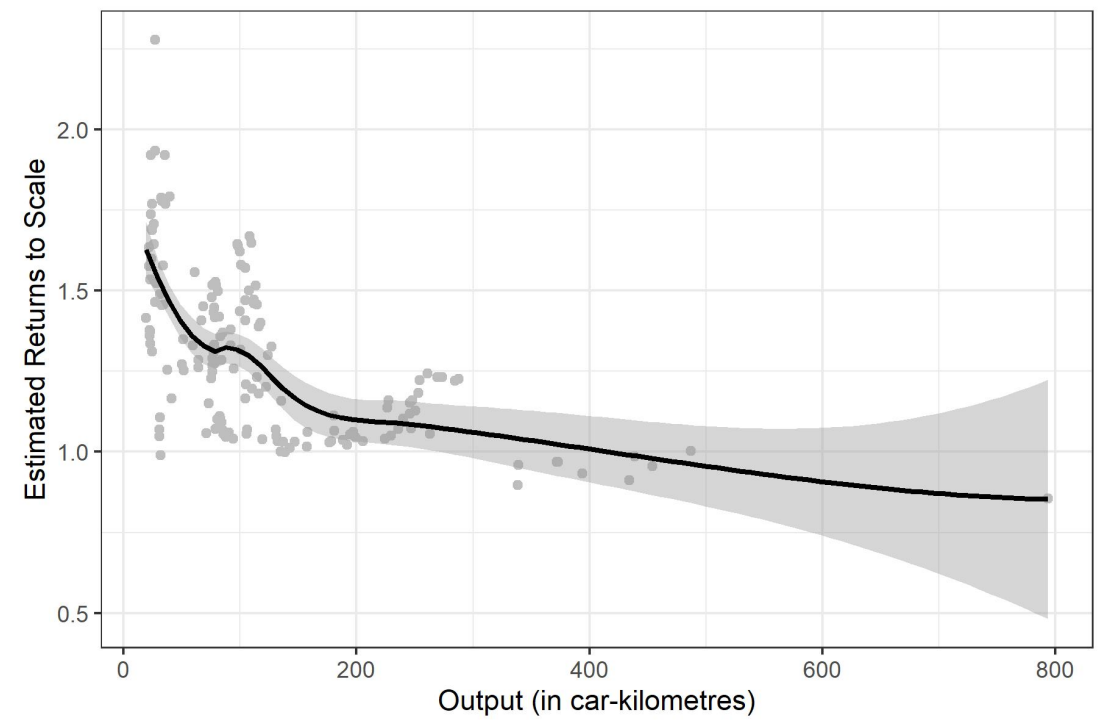

Figure 3: Variation of Returns to Scale Estimates over Output.

Figure 3 shows the variation of returns to scale estimates over a range of output (in car kilometres). We see that RTS estimates decrease approximately over output, where very large output levels approximately correspond to constant RTS, that is, equal to one. This decrease could be because very large metro systems may become less efficient in dealing with their time-varying fleet and staff requirements. 


\section{Understanding the Variation in Unit Costs across Metro Systems}

Figure 1, shows that unit costs of metro operations $\left(\frac{C}{y}\right)_{i}$ vary substantially across metro systems. This variation results from two main sources: (1) intrinsic performance of the system, $P_{i}$, and (2) exogenous variation, $\sum_{j} \theta_{j} S_{i}(j)$ from sources $S(j) s$. The adjusted costs are given by the following equation, where the left hand side represents the adjusted costs:

$$
\left(\frac{C}{y}\right)_{i}=P_{i}+\sum_{j} \theta_{j} \cdot S_{i}(j)+e_{i}
$$

To understand the variation in costs resulting from intrinsic differences in performance across metro operations, it is important to adjust for any external variation. The exogenous variation can be absorbed by adjusting for differences between $S_{i}(j) s$ across various systems and constraining them to their mean values $\overline{S_{i}(j)}$ to ensure comparability, as given by the following equation:

$$
\left(\frac{C}{y}\right)_{i}+\sum_{j} \theta_{j} \cdot\left(\overline{S_{i}(j)}-S_{i}(j)\right)=P_{i}+\sum_{j} \theta_{j} \cdot \overline{S_{i}(j)}+e_{i}
$$

For metro operations, increasing returns to density and network size in metro operations are external benefits. In this brief section, we adjust the unit costs in figure 1 for exogenous variation resulting from differences in density and network size. We use both our scale economy estimates and those from the literature. This adjustment helps us to assess whether scale economy estimates from this analysis are able to explain a greater extent of exogenous influence in unit costs as compared to the estimates from the literature.

Based on equation 3, we can represent the operational costs of metro $i, C_{i}$ as a function of its network size, $N_{i}$, its output (car-kilometres), $Y_{i}$, and a function $g(x)_{i}$ that includes other covariates like factor prices, load factor and so on, as given in equation 22 . The elasticities of cost with respect to network size and output are $\theta_{1}$ and $\theta_{2}$.

$$
C_{i}=g(x)_{i} N_{i}^{\theta_{1}} Y_{i}^{\theta_{2}}
$$


From equation 22 , unit costs of metro operations $\left(\frac{C}{Y}\right)_{i}$ can be given by:

$$
\begin{aligned}
& \left(\frac{C}{Y}\right)_{i}=g(x)_{i} N_{i}^{\theta_{1}} Y_{i}^{\left(\theta_{2}-1\right)} \\
\Longrightarrow & \left(\frac{C}{Y}\right)_{i}=g(x)_{i} N_{i}^{\left(\theta_{1}+\theta_{2}-1\right)}\left(\frac{Y}{N}\right)_{i}^{\left(\theta_{2}-1\right)} \\
\Longrightarrow & \left(\frac{C}{Y}\right)_{i}=g(x)_{i} N_{i}^{\left(\frac{1}{R T S}-1\right)}\left(\frac{Y}{N}\right)_{i}^{\left(\frac{1}{R T D}-1\right)} \\
\Longrightarrow & \log \left(\frac{C}{Y}\right)_{i}=\log g(x)_{i}+\left(\frac{1}{R T S}-1\right) \log N_{i}+\left(\frac{1}{R T D}-1\right) \log \left(\frac{Y}{N}\right)_{i}
\end{aligned}
$$

where,

$R T D=\left(\frac{\partial \log C_{i}}{\partial \log Y_{i}}\right)^{-1}=\frac{1}{\theta 2}$ and $R T S=\left(\frac{\partial \log C_{i}}{\partial \log Y_{i}}+\frac{\partial \log C_{i}}{\partial \log N_{i}}\right)^{-1}=\frac{1}{\theta 1+\theta 2}$.

We convert the unit cost equation to its equivalent logarithmic form because our $\theta_{1}$ and $\theta_{2}$ values represent elasticities rather than the absolute effect.

At this point, it is worth re-emphasising that the technology underlying production of metro output is non-homothetic and the input factors are not linearly separable (refer Section 6.2. So, our scale estimates also capture the part of variation in input factor prices and other covariates that results from differences in network size and density of operations.

Adjusting for differences in network size and density of operations in equation 23, we have:

$$
\begin{gathered}
\left.\log \left(\frac{C}{Y}\right)_{i}+\left(\frac{1}{R T S}-1\right)\left(\overline{\log N_{i}}-\log N_{i}\right)+\left(\frac{1}{R T D}-1\right) \overline{\left(\log \left(\frac{Y}{N}\right)_{i}\right.}-\log \left(\frac{Y}{N}\right)_{i}\right) \\
=\log g(x)_{i}+\left(\frac{1}{R T S}-1\right) \overline{\log N_{i}}+\left(\frac{1}{R T D}-1\right) \overline{\log \left(\frac{Y}{N}\right)_{i}}+e_{i}
\end{gathered}
$$

Figure 4 shows the variation in unit operational costs in 2015 for the same group of thirty-two metro systems as in figure 1 . The figure also shows the variation in unit operational costs adjusted using our scale economy estimates, that is, RTS $=1.223$ and $\mathrm{RTD}=1.562$, represented by adjusted unit costs (1) and those adjusted using the scale economy estimates from the literature, that is, RTS $=1.000$ and RTD $=1.400$, repre- 
sented by adjusted unit costs (2). Table 6 presents the mean, variance and coefficient of variation of unadjusted and adjusted unit operational costs.

Table 6: Mean and Standard Deviations of Unadjusted and Adjusted Unit Operational Costs.

\begin{tabular}{lccc}
\hline & Mean & Std. Error & Coefficient of Variation \\
\hline Unadjusted Unit Operational Costs (in US\$) & 5.765 & 6.206 & 0.432 \\
Unit Operational Costs adjusted using estimates from this analysis (in US\$) & 5.800 & 4.615 & 0.370 \\
Unit Operational Costs adjusted using estimates from the literature (in US\$) & 5.774 & 5.311 & 0.399 \\
\hline
\end{tabular}

From table 6 and figure 4, we find that our scale economy estimates are able to explain a greater deal of variation in unit costs of metro operations as compared to the estimates from the literature. Thus, the methodological improvement in the estimation of a metro cost function demonstrated in this paper is worthwhile and the resulting estimates from this analysis are more representative in explaining the industry-wide exogenous variation in unit costs of operations resulting from differences in network size and density of operations across metro systems.

\section{Conclusions and Policy Implications}

This paper has developed a comprehensive understanding of operational costs of urban rail transport and determined the important aspects of the technology that drives unit cost differences between metro firms. We use dynamic panel generalised method of moments (DPGMM) with a very high quality panel dataset on urban rail transport operations to estimate the underlying cost function. This paper offers the key methodological insight on controlling for observed and unobserved time-invariant and time-variant firm level sources of confounding in the estimation of a transport cost function. We illustrate that DPGMM is attractive for the cost function estimation because it permits flexible representation of unobserved productivity level differences between firms and offers better remedies for endogenous covariates. The key results that emerge from our analysis are as follows:

1. A comparison of our DPGMM results with the traditional estimation methods like pooled ordinary least squares estimation confirms that failure to account for unobserved productivity differences between firms in empirical cost analysis creates a downward bias in the estimates of RTS and RTD. 


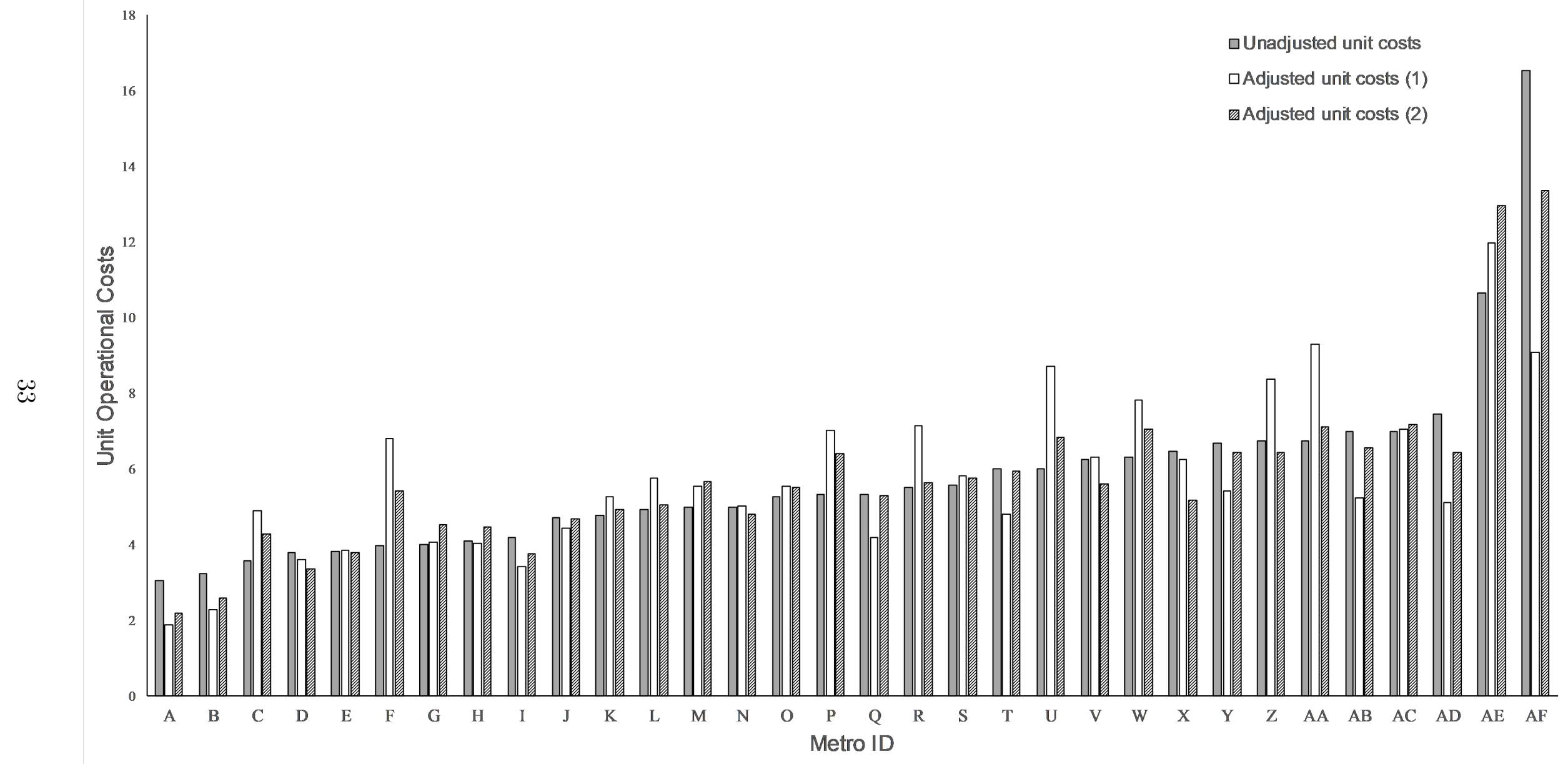

Figure 4: Variation of unit operational costs across various metro systems. 
2. Our estimate of RTD is 1.562 , which is statistically greater than one. We thus find evidence of increasing RTD that is consistent with literature on urban rail transport costs, although the average RTD estimate from the literature is around 1.40. Increasing RTD results from the existence a range of fixed and semi-fixed costs are prevalent in the urban rail transport industry that do not vary proportionally with output.

3. We find evidence of increasing RTS, which justifies the presence of large size firms in urban rail transport industry. Our RTD estimate is 1.223 , which is again statistically greater than one. The weight of evidence in the urban rail transport literature indicates that the industry is characterised by constant RTS. However, we find that controlling for endogeneity in empirical cost analysis and accounting for dynamics in firm-level productivity gives RTS estimates that is consistent with the observed industry behaviour.

4. The TSC dataset indicates that around eighty-percent of way and structure maintenance costs comprise of labour and electricity costs, which can be varied in the short-run. We, therefore, include infrastructure maintenance costs as a component of variable costs in our short-run operational cost analysis. Increasing returns to scale may have resulted from the presence of cost complementarities between operational and way and track cost components as found in case of mainline railways.

5. We also study other aspects of the underlying production technology. We find that the marginal rate of technical substitution between any two inputs for production of metro output depends on the prices of other inputs, that is, the underlying technology shows non-separability of input factors. Our results also show nonhomotheticity implying that changes in factor prices affects both cost elasticity and corresponding factor demand. Therefore, scale economies in provision of urban rail transport services are not independent of input prices.

Thus, by controlling for various sources of endogeneity in the estimation of a shortrun variable cost function for urban rail transport industry, we are able to provide more reliable estimates of industry indices for transport investment appraisal and guiding decisions on pricing rules. Our proposed methodology provides a general specification that could be useful in cost analysis in other modes of transportation, whether be mainline railways, bus or airline operations. 
We find that metro systems with high density of usage are highly cost efficient. This could be taken as an evidence in support of providing metro services in city centres where high frequency services are required to serve the travel demand. In addition, the presence of network size economies may be relevant from a policy point of view, particularly for the economic appraisal of large infrastructure projects that lead to network expansion. Returns to network size implies that such investments may generate external benefits in the form of a network-wide reduction in operational costs. It would be interesting to quantify this external benefit and assess whether it could have significant impact on the outcome of traditional cost-benefit analyses. We aim to undertake this analysis in future.

\section{References}

Ackerberg, D., Benkard, C. L., Berry, S. and Pakes, A. (2007), Econometric tools for analyzing market outcomes, in J. J. Heckman and E. E. Leamer, eds, 'Handbook of econometrics', Vol. 6A, Amsterdam and Boston: Elsevier, North-Holland, pp. 41714276.

Arellano, M. and Bond, S. (1991), 'Some tests of specification for panel data: Monte carlo evidence and an application to employment equations', The review of economic studies 58(2), 277-297.

Arellano, M. and Bover, O. (1995), 'Another look at the instrumental variable estimation of error-components models', Journal of Econometrics 68(1), 29-51.

Basso, L. J. and Jara-Diaz, S. R. (2006), 'Distinguishing multiproduct economies of scale from economies of density on a fixed-size transport network', Networks and Spatial Economics 6(2), 149-162.

Basso, L. J., Jara-Díaz, S. R. and II, W. G. W. (2011), Cost functions for transport firms, in A. de Palma, R. Lindsey, E. Quinet and R. Vickerman, eds, 'A Handbook of Transport Economics', Edward Elgar Publishing Ltd., Northampton, chapter 12, pp. 273-297.

Basso, L. J. and Jara-Díaz, S. R. (2005), 'Calculation of economies of spatial scope from transport cost functions with aggregate output with an application to the airline industry', Journal of Transport Economics and Policy (JTEP) 39(1), 25-52. 
Batarce, M. (2016), 'Estimation of urban bus transit marginal cost without cost data', Transportation Research Part B: Methodological 90, 241-262. ID: 271728.

URL: http://www.sciencedirect.com/science/article/pii/S0191261516302661

Batarce, M. and Galilea, P. (2018), 'Cost and fare estimation for the bus transit system of Santiago', Transport Policy 64, 92-101.

Beveren, I. V. (2012), 'Total factor productivity estimation: A practical review', Journal of economic surveys $\mathbf{2 6}(1), 98-128$.

Bitzan, J. D. (2000), Railroad cost conditions: implications for policy, report for the Federal Railroad Administration, Technical report, Upper Great Plains Transportation Institute, North Dakota State University.

Bitzan, J. D. (2003), 'Railroad costs and competition: The implications of introducing competition to railroad networks', Journal of Transport Economics and Policy (JTEP) $37(2), 201-225$.

Blundell, R. and Bond, S. (2000), 'GMM estimation with persistent panel data: an application to production functions', Econometric reviews 19(3), 321-340.

Borts, G. H. (1960), 'The estimation of rail cost functions', Econometrica, Journal of the Econometric Society pp. 108-131.

Caves, D. W., Christensen, L. R. and Swanson, J. A. (1981), 'Productivity growth, scale economies, and capacity utilization in US railroads, 1955-74', The American Economic Review 71(5), 994-1002.

Caves, D. W., Christensen, L. R., Tretheway, M. W. and Windle, R. J. (1987), An assessment of the efficiency effects of US airline deregulation via an international comparison, in E. E. Bailey, ed., 'Public Regulation: New Perspectives on Institutions and Policies', MIT Press, Cambridge, pp. 285-320.

Collard-Wexler, A. (2012), Production and cost functions. Unpublished.

URL: https://pdfs.semanticscholar.org/1fbc/f9c7743c585f0740297be1b1a37ac8b89fr7.pdf.

De-Loecker, J. (2011), 'Product differentiation, multiproduct firms, and estimating the impact of trade liberalization on productivity.', Econometrica 79(5), 1407-1451. 
Farsi, M., Filippini, M. and Greene, W. (2005), 'Efficiency measurement in network industries: application to the Swiss railway companies', Journal of Regulatory Economics 28(1), 69-90.

Filippini, M. and Maggi, R. (1992), 'The cost structure of the Swiss private railways', International Journal of Transport Economics/Rivista internazionale di economia dei trasporti 19(3), 307-327.

Friedlaender, A. F. and Spady, R. H. (1981), Freight transport regulation: Equity, efficiency and competition in the rail and trucking industries, MIT Press, Cambridge.

Gagnepain, P. and Ivaldi, M. (2002), 'Incentive regulatory policies: The case of public transit systems in France', The Rand journal of economics 33(4), 605-629.

Graham, D. J. (2008), 'Productivity and efficiency in urban railways: Parametric and non-parametric estimates', Transportation Research Part E: Logistics and Transportation Review 44(1), 84-99.

Graham, D. J., Couto, A., Adeney, W. E. and Glaister, S. (2003), 'Economies of scale and density in urban rail transport: effects on productivity', Transportation Research Part E: Logistics and Transportation Review 39(6), 443-458.

Greene, W. H. (1980), 'Maximum likelihood estimation of econometric frontier functions', Journal of Econometrics 13(1), 27-56.

Hensher, D. A., Daniels, R. and Demellow, I. (1995), 'A comparative assessment of the productivity of Australia's public rail systems 1971/72-1991/92', Journal of Productivity Analysis 6(3), 201-223.

Ivaldi, M. and McCullough, G. (2007), 'Railroad pricing and revenue-to-cost margins in the post-staggers era', Research in Transportation Economics 20, 153-178.

Jara-Diaz, S. R. (1982), 'The estimation of transport cost functions: a methodological review', Transport Reviews 2(3), 257-278.

Jara-Diaz, S. R. and Cortes, C. E. (1996), 'On the calculation of scale economies from transport cost functions', Journal of Transport Economics and Policy pp. 157-170. 
Karlaftis, M. G. and McCarthy, P. (2002), 'Cost structures of public transit systems: a panel data analysis', Transportation Research Part E: Logistics and Transportation Review 38(1), 1-18.

Karlaftis, M. G., McCarthy, P. S. and Sinha, K. C. (1999), 'System size and cost structure of transit industry', Journal of Transportation Engineering 125(3), 208-215.

Katayama, H., Lu, S. and Tybout, J. R. (2009), 'Firm-level productivity studies: illusions and a solution', International Journal of Industrial Organization 27(3), 403-413.

Keeler, T. E. (1974), 'Railroad costs, returns to scale, and excess capacity', The review of economics and statistics 56(2), 201-208.

Levinsohn, J. and Petrin, A. (2003), 'Estimating production functions using inputs to control for unobservables', The Review of Economic Studies 70(2), 317-341.

Litman, T. (2004), 'Transit price elasticities and cross-elasticities', Journal of Public Transportation $\mathbf{7}(2), 3$.

McFadden, D. (1978), Cost, revenue, and profit functions, in M. Fuss and D. McFadden, eds, 'Production Economics: A Dual Approach to Theory and Application', Vol. 1, Amsterdam: North Holland.

McGeehan, H. (1993), 'Railway costs and productivity growth: The case of the Republic of Ireland, 1973-1983', Journal of Transport Economics and Policy pp. 19-32.

Mizutani, F. (2004), 'Privately owned railways' cost function, organization size and ownership', Journal of Regulatory Economics 25(3), 297-322.

Ogawa, K. (2011), 'Why are concavity conditions not satisfied in the cost function? the case of Japanese manufacturing firms during the bubble period', Oxford Bulletin of Economics and Statistics 73(4), 556-580.

Olley, G. S. and Pakes, A. (1996), 'The dynamics of productivity in the telecommunications equipment industry', Econometrica 64(6), 1263-1297.

URL: http://www.jstor.org/stable/2171831

Oum, T. H. and Waters, W. G. (1996), 'A survey of recent developments in transportation cost function research', Logistics and Transportation Review 32(4), 423-463. 
Pindyck, R. S. and Rotemberg, J. J. (1983), 'Dynamic factor demands and the effects of energy price shocks', The American Economic Review 73(5), 1066-1079.

Pozdena, R. J. and Merewitz, L. (1978), 'Estimating cost functions for rail rapid transit properties', Transportation Research 12(2), 73-78.

Rios-Rull, J.-V. and Santaeulalia-Llopis, R. (2010), 'Redistributive shocks and productivity shocks', Journal of Monetary Economics 57(8), 931-948.

Ryana, D. L. and Wales, T. J. (2000), 'Imposing local concavity in the translog and generalized Leontief cost functions', Economics Letters 67(3), 253-260.

Sànchez, P. C. and Villaroyya, J. M. (2000), 'Efficiency, technical change and productivity in the European rail sector: a stochastic frontier approach', International Journal of Transport Economics/Rivista internazionale di economia dei trasporti 27(1), 55-76.

Savage, I. (1997), 'Scale economies in United States rail transit systems', Transportation Research Part A: Policy and Practice 31(6), 459-473.

Small, K. A., Verhoef, E. T. and Lindsey, R. (2007), The economics of urban transportation, Routledge, New York.

UN-DESA (2018), The 2018 revision of world urbanization prospects, Technical report, Department of Economic and Social Affairs, United Nations.

URL: https://esa.un.org/unpd/wup

Viton, P. A. (1981), 'A translog cost function for urban bus transit', The Journal of Industrial Economics pp. 287-304.

Wei, W. and Hansen, M. (2003), 'Cost economics of aircraft size', Journal of Transport Economics and Policy (JTEP) 37(2), 279-296.

Wills-Johnson, N. (2010), 'Cost functions for Australia's railways', Journal of Infrastructure Systems 17(1), 1-14.

Wooldridge, J. M. (2009), 'On estimating firm-level production functions using proxy variables to control for unobservables', Economics Letters 104(3), 112-114. 


\section{Appendix A}

Table 7: Summary of key literature on the existence of RTS and RTD in transport operations in the short-run.

\begin{tabular}{|c|c|c|c|c|c|c|c|c|}
\hline Author(s) & Country & Data & $\begin{array}{l}\text { Dependent } \\
\text { Variable }\end{array}$ & $\begin{array}{l}\text { Functional } \\
\text { Form }\end{array}$ & $\begin{array}{l}\text { Measure } \\
\text { of Output }\end{array}$ & $\begin{array}{l}\text { Estimation } \\
\text { Methodology }\end{array}$ & $\begin{array}{l}\text { Returns } \\
\text { to Scale }\end{array}$ & $\begin{array}{l}\text { Returns } \\
\text { to Density }\end{array}$ \\
\hline \multicolumn{9}{|l|}{ Studies on Mainline Railway: } \\
\hline Wills-Johnson (2010) & Australia & 1900-1992 & Total Cost & Translog & Multi-output & POLS & Increasing & Increasing \\
\hline Ivaldi and McCullough (2007) & US & $1981-2004$ & Total Cost & Translog & Car-miles & ML & Increasing & \\
\hline Farsi et al. (2005) & Switzerland & 1985-1997 & Total Cost & Cobb-Douglas & Multi-output & POLS, RE, FE & Increasing & Increasing \\
\hline Mizutani (2004) & Japan & $1970-2000$ & Variable Cost & Translog & Vehicle-kilometres & ML & Increasing & Increasing \\
\hline Bitzan (2003) & US & 1983-1997 & Variable Cost & Translog & Ton-miles & FE & Increasing & Increasing \\
\hline Sànchez and Villaroyya (2000) & Europe & 1970-1990 & Total Cost & Translog & Multi-output & SFA & Constant & \\
\hline Hensher et al. (1995) & Australia & 1971-1992 & TFP index & Parametric & Multi-output & POLS & & Increasing \\
\hline McGeehan (1993) & Ireland & 1973-1983 & Variable Cost & Translog & Multi-output & POLS & & Increasing \\
\hline Filippini and Maggi (1992) & Switzerland & $1985-1988$ & Total Cost & Translog & Wagon-kilometres & POLS & Increasing & Increasing \\
\hline Caves et al. (1981) & US & $1955-1974$ & Variable Cost & Translog & Multi-output & POLS & Constant & \\
\hline Keeler (1974) & US & 1969-1971 & Total Cost & Cobb-Douglas & Ton-miles & POLS & Constant & Increasing \\
\hline \multicolumn{9}{|l|}{ Studies on Urban Rail Transport: } \\
\hline Graham (2008) & World-wide & 1996-2007 & Output & Cobb-Douglas & Pax. journeys & POLS & Constant & Increasing \\
\hline Graham et al. (2003) & World-wide & 1996-2002 & Output & Translog & Car-kilometres & DEA/TFP & Constant & Increasing \\
\hline Gagnepain and Ivaldi (2002) & France & $1985-1993$ & Total Cost & Cobb-Douglas & Seat-kilometres & SFA & Increasing & \\
\hline Savage (1997) & US & $1985-1991$ & Variable cost & Translog & Multi-output & IV: 3SLS & Constant & Increasing \\
\hline Pozdena and Merewitz (1978) & US & $1960-1970$ & Total cost & Cobb-Douglas & Vehicle-miles & POLS & Increasing & Increasing \\
\hline \multicolumn{9}{|l|}{ Studies on Urban Bus Transport: } \\
\hline $\begin{array}{l}\text { Karlaftis and McCarthy (2002); } \\
\text { Karlaftis et al. (1999) }\end{array}$ & US & 1986-1994 & Variable cost & Translog & Vehicle-miles & POLS & $\begin{array}{l}\text { Increasing } \\
\text { (small sys.) }\end{array}$ & $\begin{array}{l}\text { Increasing } \\
\text { (large sys.) }\end{array}$ \\
\hline & & & & & & & $\begin{array}{l}\text { Decreasing } \\
\text { (large sys.) }\end{array}$ & $\begin{array}{l}\text { Decreasing } \\
\text { (suburban) }\end{array}$ \\
\hline Viton (1981) & US & 1975 & Variable cost & Translog & Vehicle-miles & POLS & $\begin{array}{l}\text { Decreasing } \\
\text { (large systems) }\end{array}$ & Increasing \\
\hline
\end{tabular}

*POLS: Pooled Ordinary Least Squares; FE: Fixed Effects; RE: Random Effects, IV: Instrumental Variables, 3SLS: Three stage least squares

**SFA: Stochastic Frontier Analysis, TFP: Total Factor Productivity, DEA: Data Envelopment Analysis, ML: Maximum Likelihood

*** pax. stands for passengers and sys. for systems 


\section{Appendix B}

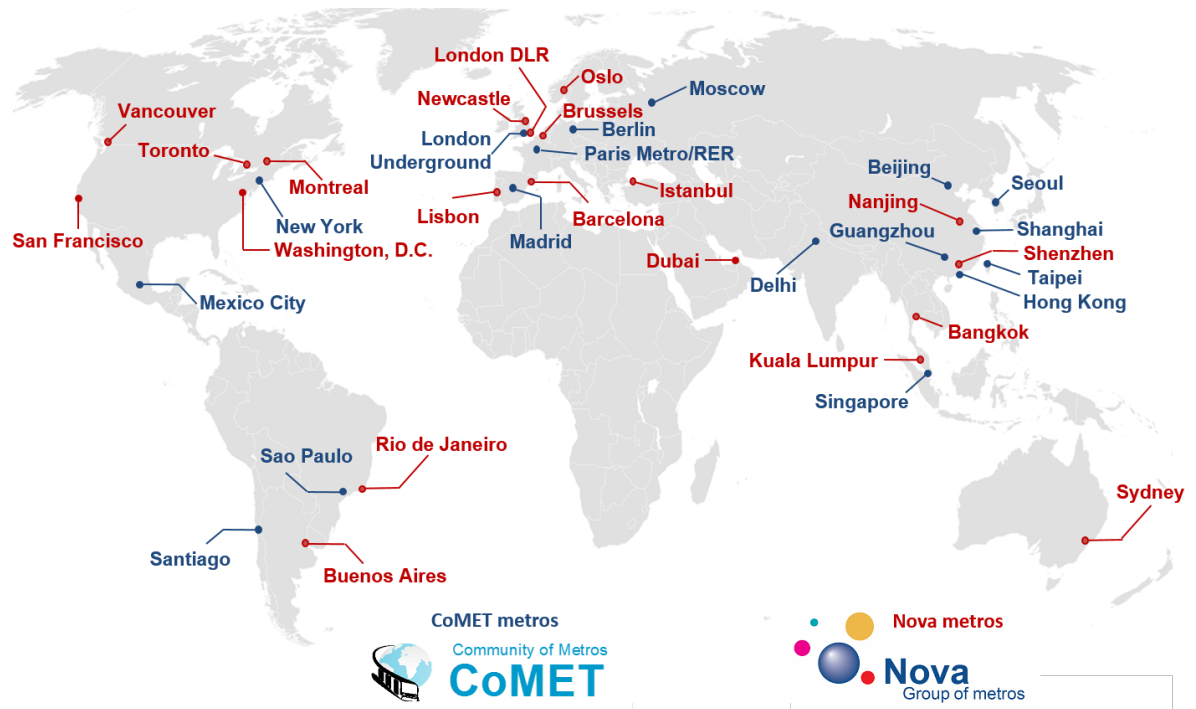

Figure 5: Metro operations reported in the TSC data.

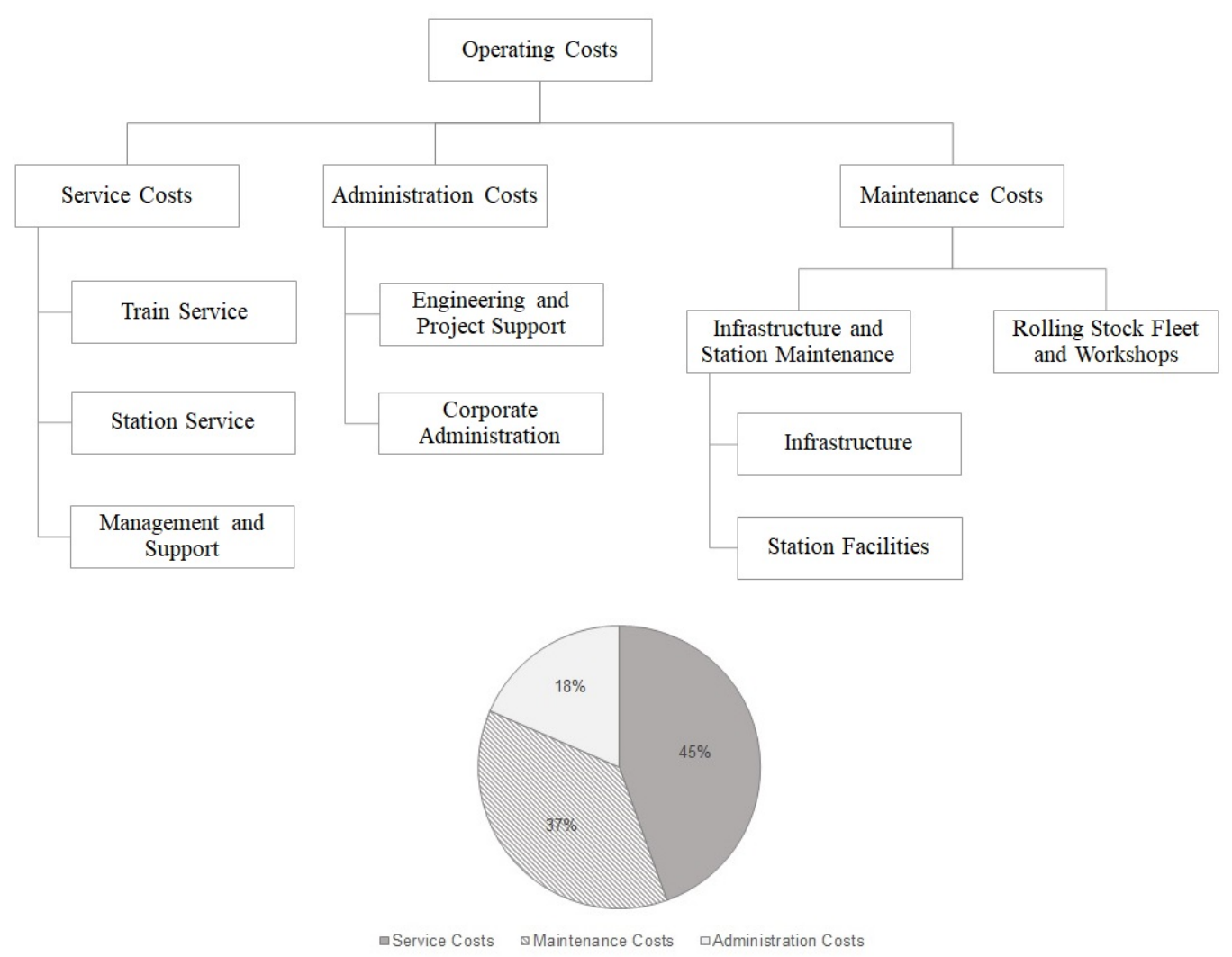

Figure 6: Components of metro operational costs as in the TSC data. 


\section{Appendix $\mathrm{C}$}

Table 8: Summary of Results of the Short-run Cost Model.

\begin{tabular}{|c|c|c|c|c|c|}
\hline \multirow{2}{*}{$\begin{array}{l}\text { Explanatory variables (logarithms } \\
\text { except for dummy variables) }\end{array}$} & \multicolumn{3}{|c|}{ Static Panel Models } & \multicolumn{2}{|c|}{ Dynamic Panel Models } \\
\hline & POLS & $\mathrm{FE}$ & IV: Sys GMM & AR(1): Diff GMM & AR(1): Sys GMM \\
\hline \multirow[t]{2}{*}{ Car kms } & $0.815^{* * *}$ & $0.506^{* * *}$ & $0.838^{* * *}$ & $0.472^{* * *}$ & $0.640 * * *$ \\
\hline & $(0.063)$ & $(0.078)$ & $(0.141)$ & $(0.110)$ & $(0.116)$ \\
\hline \multirow[t]{2}{*}{ Network length } & $0.142^{* *}$ & $0.264^{* * *}$ & 0.140 & $0.356^{* * *}$ & $0.177^{*}$ \\
\hline & $(0.069)$ & $(0.079)$ & $(0.124)$ & $(0.109)$ & $(0.097)$ \\
\hline \multirow[t]{2}{*}{ Load Factor } & $0.340^{* * *}$ & $0.173^{* *}$ & $0.312^{*}$ & $0.261 *$ & $0.298^{*}$ \\
\hline & $(0.093)$ & $(0.070)$ & $(0.186)$ & $(0.136)$ & $(0.160)$ \\
\hline \multirow[t]{2}{*}{ Labour Price } & $0.574^{* * *}$ & $0.642^{* * *}$ & $0.578^{* * *}$ & $0.634^{* * *}$ & $0.485^{* * *}$ \\
\hline & $(0.046)$ & $(0.036)$ & $(0.055)$ & $(0.052)$ & $(0.048)$ \\
\hline \multirow[t]{2}{*}{ Energy Price } & $0.231^{* * *}$ & $0.177^{* * *}$ & $0.240 * * *$ & $0.188^{* * *}$ & $0.208^{* * *}$ \\
\hline & $(0.036)$ & $(0.034)$ & $(0.052)$ & $(0.050)$ & $(0.046)$ \\
\hline \multirow[t]{2}{*}{ Residual Price } & $0.195^{* * *}$ & $0.181^{* * *}$ & $0.182^{* * *}$ & $0.178^{* * *}$ & $0.307^{* * *}$ \\
\hline & $(0.048)$ & $(0.021)$ & $(0.063)$ & $(0.023)$ & $(0.056)$ \\
\hline \multirow[t]{2}{*}{ Car kms ${ }^{2}$} & -0.026 & $0.306^{* * *}$ & 0.133 & $0.224^{* *}$ & 0.390 \\
\hline & $(0.143)$ & $(0.113)$ & $(0.386)$ & $(0.108)$ & $(0.299)$ \\
\hline \multirow[t]{2}{*}{ Network length ${ }^{2}$} & -0.046 & $0.303^{* *}$ & 0.058 & $0.289^{* *}$ & 0.322 \\
\hline & $(0.174)$ & $(0.148)$ & $(0.371)$ & $(0.131)$ & $(0.288)$ \\
\hline \multirow[t]{2}{*}{ Load Factor ${ }^{2}$} & 0.145 & 0.164 & 0.278 & 0.172 & 0.376 \\
\hline & $(0.187)$ & $(0.132)$ & $(0.323)$ & $(0.205)$ & $(0.278)$ \\
\hline \multirow[t]{2}{*}{ Labour Price $^{2}$} & $0.134^{* * *}$ & $0.177^{* * *}$ & 0.176 & $0.152^{* * *}$ & $0.140^{*}$ \\
\hline & $(0.052)$ & $(0.036)$ & $(0.117)$ & $(0.051)$ & $(0.083)$ \\
\hline \multirow[t]{2}{*}{ Energy Price ${ }^{2}$} & $0.121^{* * *}$ & $0.100^{* * *}$ & $0.134^{* *}$ & $0.092^{* * *}$ & $0.162^{* * *}$ \\
\hline & $(0.039)$ & $(0.031)$ & $(0.054)$ & $(0.035)$ & $(0.060)$ \\
\hline \multirow[t]{2}{*}{ Residual Price $^{2}$} & 0.007 & 0.008 & -0.009 & 0.000 & 0.011 \\
\hline & $(0.037)$ & $(0.013)$ & $(0.036)$ & $(0.016)$ & $(0.032)$ \\
\hline \multirow[t]{2}{*}{ Car kms x Network length } & 0.152 & $-0.559 * *$ & -0.109 & $-0.444^{* *}$ & -0.640 \\
\hline & $(0.316)$ & $(0.255)$ & $(0.744)$ & $(0.221)$ & $(0.579)$ \\
\hline \multirow[t]{2}{*}{ Car kms x Load Factor } & $0.839^{* * *}$ & $-0.690 * * *$ & $0.676^{*}$ & $-0.727^{* * *}$ & 0.244 \\
\hline & $(0.252)$ & $(0.180)$ & $(0.395)$ & $(0.282)$ & $(0.410)$ \\
\hline \multirow{2}{*}{ Car kms x Labour Price } & $0.224^{* *}$ & $-0.244^{* * *}$ & $0.202^{*}$ & -0.184 & 0.028 \\
\hline & $(0.095)$ & $(0.090)$ & $(0.121)$ & $(0.117)$ & $(0.159)$ \\
\hline \multirow[t]{2}{*}{ Car kms x Energy Price } & $-0.297^{* * *}$ & $0.227^{* * *}$ & $-0.267^{*}$ & $0.189^{*}$ & -0.200 \\
\hline & $(0.095)$ & $(0.080)$ & $(0.140)$ & $(0.106)$ & $(0.158)$ \\
\hline \multirow[t]{2}{*}{ Car kms x Residual Price } & 0.072 & 0.017 & 0.065 & -0.005 & $0.172^{* *}$ \\
\hline & $(0.087)$ & $(0.039)$ & $(0.105)$ & $(0.041)$ & $(0.076)$ \\
\hline \multirow[t]{2}{*}{ Network length x Load Factor } & $-1.312^{* * *}$ & $0.713^{* * *}$ & $-1.180^{* * *}$ & $0.723^{* *}$ & -0.628 \\
\hline & $(0.312)$ & $(0.216)$ & $(0.416)$ & $(0.354)$ & $(0.448)$ \\
\hline \multirow[t]{2}{*}{ Network length $\mathrm{x}$ Labour Price } & $-0.403^{* * *}$ & $0.178^{*}$ & $-0.396^{* * *}$ & 0.143 & -0.210 \\
\hline & $(0.123)$ & $(0.103)$ & $(0.111)$ & $(0.132)$ & $(0.157)$ \\
\hline \multirow[t]{2}{*}{ Network length x Energy Price } & $0.438^{* * *}$ & $-0.188^{* *}$ & $0.421^{* * *}$ & $-0.184^{*}$ & $0.340^{* *}$ \\
\hline & $(0.112)$ & $(0.085)$ & $(0.136)$ & $(0.102)$ & $(0.147)$ \\
\hline \multirow[t]{2}{*}{ Network length x Residual Price } & -0.035 & 0.010 & -0.024 & 0.040 & -0.130 \\
\hline & $(0.095)$ & $(0.043)$ & $(0.100)$ & $(0.044)$ & $(0.103)$ \\
\hline Load Factor x Labour Price & $0.350^{* *}$ & $0.236^{* *}$ & $0.466^{* *}$ & 0.237 & $0.506^{* * *}$ \\
\hline
\end{tabular}


Table 8 Continued from previous page.

\begin{tabular}{|c|c|c|c|c|c|}
\hline \multirow{2}{*}{$\begin{array}{l}\text { Explanatory variables (logarithms } \\
\text { except for dummy variables) }\end{array}$} & \multicolumn{3}{|c|}{ Static Panel Models } & \multicolumn{2}{|c|}{ Dynamic Panel Models } \\
\hline & POLS & $\mathrm{FE}$ & IV: Sys GMM & AR(1): Diff GMM & AR(1): Sys GMM \\
\hline & $(0.138)$ & $(0.097)$ & $(0.229)$ & $(0.164)$ & $(0.188)$ \\
\hline \multirow[t]{2}{*}{ Load Factor x Energy Price } & $-0.321 * * *$ & $-0.245^{* *}$ & $-0.401^{* *}$ & -0.247 & $-0.459^{* * *}$ \\
\hline & $(0.108)$ & $(0.099)$ & $(0.180)$ & $(0.155)$ & $(0.156)$ \\
\hline \multirow[t]{2}{*}{ Load Factor x Residual Price } & -0.029 & 0.009 & -0.065 & 0.010 & -0.047 \\
\hline & $(0.080)$ & $(0.039)$ & $(0.125)$ & $(0.040)$ & $(0.092)$ \\
\hline \multirow{2}{*}{ Labour Price x Energy Price } & $-0.124^{* * *}$ & $-0.135^{* * *}$ & $-0.159 * *$ & $-0.122^{* * *}$ & $-0.145^{* *}$ \\
\hline & $(0.041)$ & $(0.029)$ & $(0.080)$ & $(0.039)$ & $(0.066)$ \\
\hline \multirow[t]{2}{*}{ Labour Price x Residual Price } & -0.010 & $-0.043^{* *}$ & -0.017 & -0.030 & 0.005 \\
\hline & $(0.038)$ & $(0.020)$ & $(0.060)$ & $(0.023)$ & $(0.049)$ \\
\hline \multirow[t]{2}{*}{ Energy Price x Residual Price } & 0.003 & $0.035^{* *}$ & 0.025 & 0.030 & -0.016 \\
\hline & $(0.040)$ & $(0.018)$ & $(0.064)$ & $(0.019)$ & $(0.046)$ \\
\hline \multirow[t]{2}{*}{ Lag (Dependent Variable) } & - & - & - & 0.020 & $0.196^{* * *}$ \\
\hline & & & & $(0.016)$ & $(0.064)$ \\
\hline Year Effects Included & YES & YES & YES & YES & YES \\
\hline No. of Observations & 165 & 165 & 140 & 119 & 119 \\
\hline Adjusted R - square & 0.974 & 0.998 & - & - & - \\
\hline \multirow[t]{2}{*}{ Arellano-Bond test for $\mathrm{AR}(1)$} & - & - & $\mathrm{z}=-1.59$ & $\mathrm{z}=-1.93$ & $\mathrm{z}=-1.86$ \\
\hline & & & $\operatorname{Pr}>\mathrm{z}=0.112$ & $\operatorname{Pr}>\mathrm{z}=0.053$ & $\operatorname{Pr}>\mathrm{z}=0.052$ \\
\hline Arellano-Bond test for $\mathrm{AR}(2)$ & - & - & $\mathrm{z}=0.14$ & $\mathrm{z}=-1.91$ & $\mathrm{z}=-1.21$ \\
\hline & & & $\operatorname{Pr}>\mathrm{z}=0.891$ & $\operatorname{Pr}>\mathrm{z}=0.056$ & $\operatorname{Pr}>\mathrm{z}=0.226$ \\
\hline Sargan Test & - & - & $\chi^{2}(126)=1181.96$ & $\chi^{2}(84)=180.50$ & $\chi^{2}(103)=412.14$ \\
\hline & & & $\operatorname{Pr}>\chi^{2}=0.000$ & $\operatorname{Pr}>\chi^{2}=0.000$ & $\operatorname{Pr}>\chi^{2}=0.000$ \\
\hline No. of Instruments & - & - & 161 & 119 & 131 \\
\hline \multirow[t]{2}{*}{ Returns to Density (RTD) } & $1.227^{* * *}$ & $1.978^{* * *}$ & $1.193^{* * *}$ & $2.119^{* * *}$ & $1.562^{* * *}$ \\
\hline & $(0.096)$ & $(0.306)$ & $(0.201)$ & $(0.492)$ & $(0.283)$ \\
\hline \multirow[t]{2}{*}{ Returns to Scale (RTS) } & $1.045^{* * *}$ & $1.300^{* * *}$ & $1.023^{* * *}$ & $1.207^{* * *}$ & $1.223^{* * *}$ \\
\hline & $(0.028)$ & $(0.079)$ & $(0.058)$ & $(0.081)$ & $(0.081)$ \\
\hline
\end{tabular}

(i) Figures in brackets denote the standard errors associated with the estimates.

(ii) Significance: $(* * *) 99$ percent, (**) 95 percent, $(*) 90$ percent.

(iii) Estimation Methods from left to right increase in terms of flexibility and provide more control for endogeneity.

Table 9: Summary of RTD and RTS estimates obtained using different methodologies.

\begin{tabular}{lrrrrrrrr}
\hline Estimation & \multicolumn{4}{c}{ Returns to Density (RTD) } & \multicolumn{4}{c}{ Returns to Scale (RTS) } \\
Methodology & Coef. & Std. Err. & $95 \%$ C.I. & Coef. & Std. Err. & $95 \%$ C.I. \\
\hline POLS & 1.227 & 0.0956 & 1.040 & 1.414 & 1.045 & 0.028 & 0.989 & 1.101 \\
FE & 1.978 & 0.306 & 1.378 & 2.578 & 1.300 & 0.079 & 1.145 & 1.455 \\
IV (Sys. GMM) & 1.193 & 0.201 & 0.799 & 1.587 & 1.023 & 0.058 & 0.909 & 1.137 \\
AR(1) (Diff. GMM) & 2.119 & 0.492 & 1.155 & 3.082 & 1.207 & 0.081 & 1.048 & 1.366 \\
AR(1) (Sys. GMM) & 1.562 & 0.283 & 1.006 & 2.117 & 1.223 & 0.081 & 1.065 & 1.381 \\
\hline *Coef. stands for estimated Coefficient; Std. Err for associated Standard Error \\
** C.I. denotes Confidence Interval
\end{tabular}




\section{Appendix D}

In this section, we carry out robustness checks to test the sensitivity of our results to treatment of factor prices, that is, labour price, energy price and residual prices, as exogenous instead of endogenous as in our proposed model. For the purpose of demonstration, we use a Cobb Douglas cost function as using this functional specification allows for direct comparison of parameter estimates from the cost model. We apply the System GMM estimation. We find that the parameter estimates of the cost model, and thus the scale economy estimates are not substantively different in the two cases. ${ }^{18}$

Table 10: Robustness checks against treatment of factor prices as endogenous.

\begin{tabular}{lcc}
\hline Explanatory variable & $\begin{array}{c}\text { Estimate with factor prices } \\
\text { treated as endogenous }\end{array}$ & $\begin{array}{c}\text { Estimate with factor prices } \\
\text { treated as exogenous }\end{array}$ \\
\hline Car kms & $0.571(0.111)^{* * *}$ & $0.557(0.102)^{* * *}$ \\
Network length & $0.347(0.127)^{* * *}$ & $0.361(0.112)^{* * *}$ \\
Load Factor & $0.643(0.125)^{* * *}$ & $0.658(0.127)^{* * *}$ \\
Labour Price & $0.691(0.044)^{* * *}$ & $0.701(0.044)^{* * *}$ \\
Energy Price & $0.094(0.062)$ & $0.090(0.066)$ \\
Residual Price & $0.214(0.040)^{* * *}$ & $0.209(0.047)^{* * *}$ \\
Lag (Dependent Variable) & $0.076(0.042)^{*}$ & $0.080(0.048)^{*}$ \\
\hline Year Effects Included & YES & 119 \\
No. of Observations & 119 & 131 \\
No. of Instruments & 134 & $\mathrm{z}=-1.84, \operatorname{Pr}>\mathrm{z}=0.066$ \\
Arellano-Bond test for AR(1) & $\mathrm{z}=-1.98, \operatorname{Pr}>\mathrm{z}=0.048$ & $\mathrm{z}=-0.91, \operatorname{Pr}>\mathrm{z}=0.365$ \\
Arellano-Bond test for AR(2) & $\mathrm{z}=-0.96, \mathrm{Pr}>\mathrm{z}=0.339$ & $1.089(0.039)^{* * *}$ \\
Sargan Test of over-identifying restrictions: & $\chi^{2}(113)=417.85, \operatorname{Pr}>\chi^{2}=0.00$ & $\chi^{2}(110)=391.30, \operatorname{Pr}>\chi^{2}=0.00$ \\
Returns to Scale (RTS) & $1.088(0.039)^{* * *}$ & $1.796(0.328)^{* * *}$ \\
Returns to Density (RTD) & $1.750(0.340)^{* * *}$ &
\end{tabular}

(1) All explanatory variables are in their logarithmic form except for dummy variables.

(2) Significance: $(* * *) 99$ percent, (**) 95 percent, (*) 90 percent.

(3) Figures in bracket indicate the associated robust standard errors.

\footnotetext{
${ }^{18}$ Similar tests have been carried out for a translog specification and the resulting RTD and RTS estimates have been found to be substantively the same. Results can be produced upon request.
} 


\section{Appendix E}

In this section, we carry out robustness checks to test the sensitivity of our results to exclusion of residual price as one of the factor prices from our proposed cost model. For the purpose of demonstration, we use a Cobb Douglas cost function as using this functional specification allows for direct comparison of parameter estimates from the cost model. We apply the System GMM estimation. We find that the parameter estimates when residual prices are excluded from the cost model are not very plausible as the scale economy estimates are unreasonably high. ${ }^{19}$

Table 11: Robustness checks against inclusion of residual prices in the cost model.

\begin{tabular}{lcc}
\hline Explanatory variable & $\begin{array}{c}\text { Estimate with residual price } \\
\text { included in the model }\end{array}$ & $\begin{array}{c}\text { Estimate with residual price } \\
\text { excluded from the model }\end{array}$ \\
\hline Car kms & $0.571(0.111)^{* * *}$ & $0.217(0.109)^{* *}$ \\
Network length & $0.347(0.127)^{* * *}$ & $0.259(0.079)^{* * *}$ \\
Load Factor & $0.643(0.125)^{* * *}$ & $0.412(0.079)^{* * *}$ \\
Labour Price & $0.691(0.044)^{* * *}$ & $0.385(0.064)^{* * *}$ \\
Energy Price & $0.094(0.062)$ & $0.615(0.064)^{* * *}$ \\
Residual Price & $0.214(0.040)^{* * *}$ & - \\
Lag (Dependent Variable) & $0.076(0.042)^{*}$ & $0.560(0.090)^{* * *}$ \\
\hline Year Effects Included & YES & 119 \\
No. of Observations & 119 & 131 \\
No. of Instruments & 134 & $\mathrm{z}=-3.11, \operatorname{Pr}>\mathrm{z}=0.002$ \\
Arellano-Bond test for AR(1) & $\mathrm{z}=-1.98, \operatorname{Pr}>\mathrm{z}=0.048$ & $\mathrm{z}=-0.44, \operatorname{Pr}>\mathrm{z}=0.662$ \\
Arellano-Bond test for AR(2) & $\mathrm{z}=-0.96, \mathrm{Pr}>\mathrm{z}=0.339$ & $\chi^{2}(109)=209.18, \operatorname{Pr}>\chi^{2}=0.00$ \\
Sargan Test of over-identifying restrictions: & $\chi^{2}(113)=417.85, \mathrm{Pr}>\chi^{2}=0.00$ & $2.098(0.374)^{* * *}$ \\
Returns to Scale (RTS) & $1.088(0.039)^{* * *}$ & $4.604(2.306)^{* *}$ \\
Returns to Density (RTD) & $1.750(0.340)^{* * *}$ &
\end{tabular}

(1) All explanatory variables are in their logarithmic form except for dummy variables.

(2) Significance: $(* * *) 99$ percent, $\left(^{* *}\right) 95$ percent, $\left(^{*}\right) 90$ percent.

(3) Figures in bracket indicate the associated robust standard errors.

\footnotetext{
${ }^{19}$ Similar tests have been carried out for a translog specification and the resulting RTD and RTS estimates for the cost model without residual costs have been found to be unreasonably high. Results can be produced upon request.
} 


\section{Appendix F}

In this section, we present the annual variation in the variables used in this analysis for different metro systems. Due to the sensitive commercial nature of the data, we have presented the figures in an anonymised form.

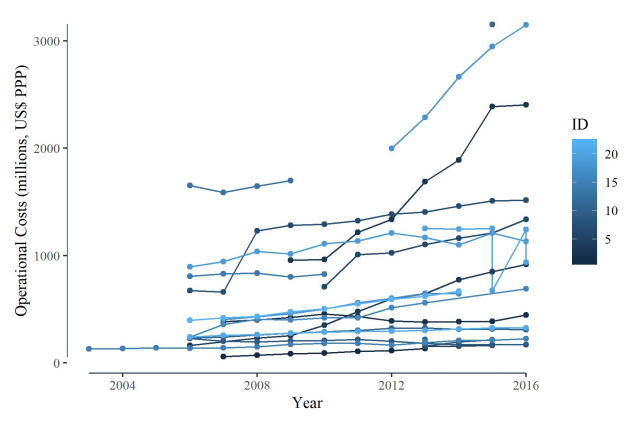

(a) Total Operational Costs

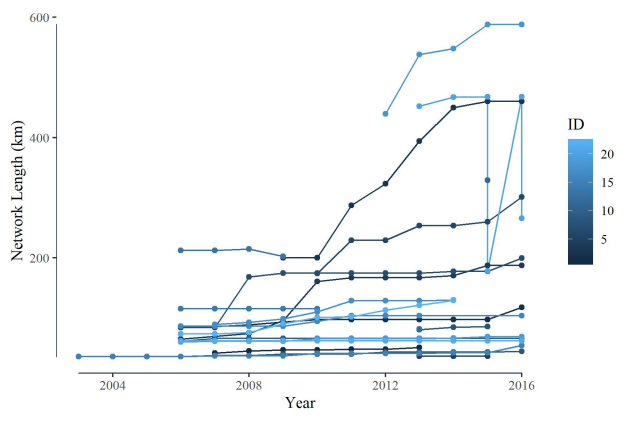

(c) Network Size

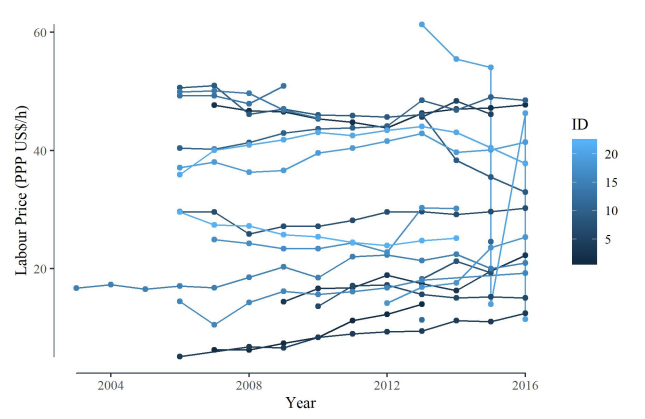

(e) Labour Price

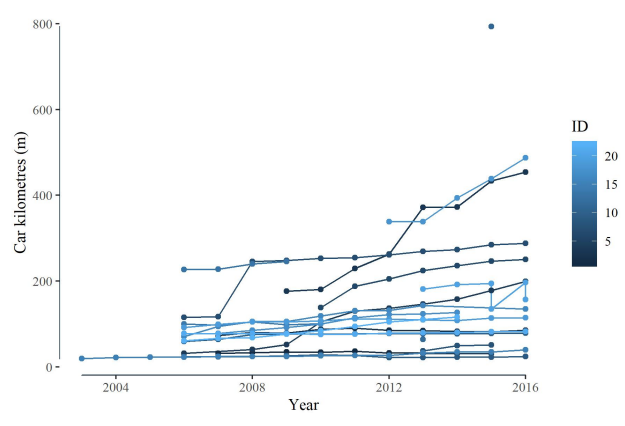

(b) Output

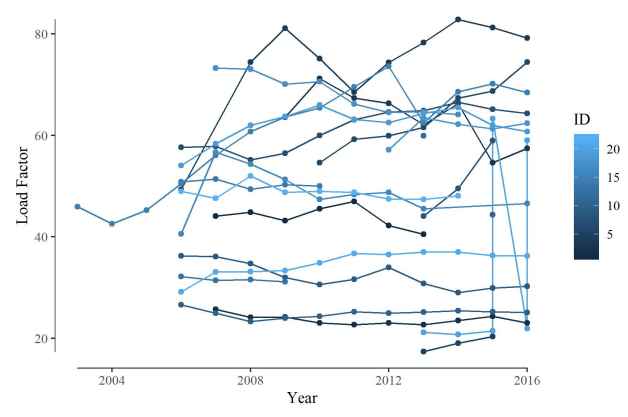

(d) Load Factor

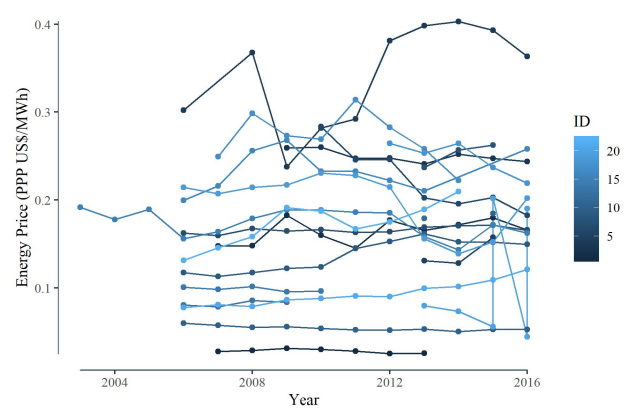

(f) Energy Price

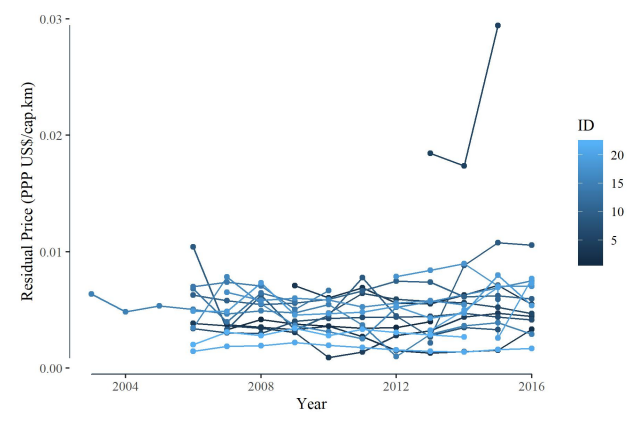

(g) Residual Price

Figure 7: Annual variation in total operational costs and its descriptors for different metro systems. 